\title{
Microbiome of Odontogenic Abscesses
}

\author{
Sebastian Böttger ${ }^{1, *} \mathbb{0}$, Silke Zechel-Gran ${ }^{2}$, Daniel Schmermund ${ }^{1}$, Philipp Streckbein ${ }^{1} \oplus$, Jan-Falco Wilbrand ${ }^{1}{ }^{1}$, \\ Michael Knitschke ${ }^{1}{ }^{\circ}$, Jörn Pons-Kühnemann ${ }^{3}$, Torsten Hain ${ }^{2,4}$, Markus Weigel ${ }^{2}{ }^{\circledR}$, Hans-Peter Howaldt ${ }^{1}$, \\ Eugen Domann ${ }^{4,5}$ (i) and Sameh Attia ${ }^{1(1)}$
}

1 Department of Oral and Maxillofacial Surgery, Justus-Liebig-University Giessen, University Hospital Giessen and Marburg, Giessen, D-35392 Giessen, Germany; Daniel.Schmermund@uniklinikum-giessen.de (D.S.); Philipp.Streckbein@uniklinikum-giessen.de (P.S.); Jan-Falco.Wilbrand@uniklinikum-giessen.de (J.-F.W.); Michael.Knitschke@uniklinikum-giessen.de (M.K.); HP.Howaldt@uniklinikum-giessen.de (H.-P.H.); sameh.attia@dentist.med.uni-giessen.de (S.A.)

2 Institute of Medical Microbiology, Justus-Liebig-University Giessen, D-35392 Giessen, Germany; Silke.Zechel@mikrobio.med.uni-giessen.de (S.Z.-G.); Torsten.Hain@mikrobio.med.uni-giessen.de (T.H.); Markus.Weigel@mikrobio.med.uni-giessen.de (M.W.)

3 Institute of Medical Informatics, Justus-Liebig-University Giessen, D-35392 Giessen, Germany; Joern.Pons@informatik.med.uni-giessen.de

4 German Center for Infection Research (DZIF), Justus-Liebig-University Giessen, Partner Site Giessen-Marburg-Langen, D-35392 Giessen, Germany; Eugen.Domann@mikrobio.med.uni-giessen.de

5 Institute of Hygiene and Environmental Medicine, Justus-Liebig-University Giessen, D-35392 Giessen, Germany

* Correspondence: Sebastian.Boettger@uniklinikum-giessen.de; Tel.: +49-641-98546271

\section{check for} updates

Citation: Böttger, S.; Zechel-Gran, S.; Schmermund, D.; Streckbein, P.;

Wilbrand, J.-F.; Knitschke, M.;

Pons-Kühnemann, J.; Hain, T.; Weigel,

M.; Howaldt, H.-P.; et al. Microbiome of Odontogenic Abscesses.

Microorganisms 2021, 9, 1307.

https://doi.org/10.3390/

microorganisms 9061307

Academic Editor: Georgios

N. Belibasakis

Received: 6 May 2021

Accepted: 14 June 2021

Published: 16 June 2021

Publisher's Note: MDPI stays neutral with regard to jurisdictional claims in published maps and institutional affiliations.

\section{Copyright: (c) 2021 by the authors.} Licensee MDPI, Basel, Switzerland. This article is an open access article distributed under the terms and conditions of the Creative Commons Attribution (CC BY) license (https:// creativecommons.org/licenses/by/ $4.0 /)$.
Abstract: Severe odontogenic abscesses are regularly caused by bacteria of the physiological oral microbiome. However, the culture of these bacteria is often prone to errors and sometimes does not result in any bacterial growth. Furthermore, various authors found completely different bacterial spectra in odontogenic abscesses. Experimental 16S rRNA gene next-generation sequencing analysis was used to identify the microbiome of the saliva and the pus in patients with a severe odontogenic infection. The microbiome of the saliva and the pus was determined for 50 patients with a severe odontogenic abscess. Perimandibular and submandibular abscesses were the most commonly observed diseases at $15(30 \%)$ patients each. Polymicrobial infections were observed in $48(96 \%)$ cases, while the picture of a mono-infection only occurred twice (4\%). On average, $31.44( \pm 12.09)$ bacterial genera were detected in the pus and $41.32( \pm 9.00)$ in the saliva. In most cases, a predominantly anaerobic bacterial spectrum was found in the pus, while saliva showed a similar oral microbiome to healthy individuals. In the majority of cases, odontogenic infections are polymicrobial. Our results indicate that these are mainly caused by anaerobic bacterial strains and that aerobic and facultative anaerobe bacteria seem to play a more minor role than previously described by other authors. The 16S rRNA gene analysis detects significantly more bacteria than conventional methods and molecular methods should therefore become a part of routine diagnostics in medical microbiology.

Keywords: oral microbiome; odontogenic abscess; 16S rRNA gene analysis; polymicrobial infection; anaerobic infection

\section{Introduction}

Odontogenic abscesses are among the most common inflammatory diseases in the field of oral and maxillofacial surgery. Most of these abscesses are localized and can be successfully treated simply by abscess incision intraorally. Larger abscesses often show a tendency to spread and are usually incised extraorally using general anesthesia [1]. If left untreated, such abscesses can cause severe local and systemic complications and can even lead to death [1-3].

Although many extensive abscesses can be successfully treated by incision alone [4,5], adjuvant antibiotic therapy is often used [6], especially if the abscessing inflammation is 
medial to the mandibular bone [7]. Such an antibiotic therapy is usually carried out as a calculated therapy, as the cultural assessment of the pathogens usually takes a few days and an antibiogram (antibiotic susceptibilities and resistances) is only available after some days. However, in those patients with exceptionally severe progression of the infection, a correct antibiogram can be decisive for the further course of the disease and ultimately also for the patient's outcome [8]. The determination of the causative bacteria is therefore an important component in the diagnosis of odontogenic abscesses, especially if there are indications of an extension or a complicated course of the disease at the beginning of the therapy [9].

However, microbiological diagnostics have weaknesses. It is not always possible to sufficiently identify the causative pathogens by culture-based methods alone [10] some authors even speak of culture-negative odontogenic abscesses if it is not possible to cultivate any pathogens at all [11]. Recent detection methods, not based on culturing, and particularly $16 \mathrm{~S}$ rRNA gene analysis with subsequent gene sequencing, have shown that many bacteria of the oral cavity can only be determined with difficulty or even not at all by culture-based methods $[3,12,13]$. It has also not yet been possible to determine which bacteria of the oral and pharyngeal microbiome are exactly responsible for the acute inflammatory process and if the oral microbiome in these patients is composed differently compared to healthy people.

With advancements in sequencing technology, and particularly in next-generation sequencing-based technologies, the identification of microorganisms and community profiling has become increasingly simple and increasingly effective [14]. With these methods, massive deoxyribonucleic acid (DNA) sequencing has become possible with a much higher throughput compared to older methods, so that a large number of samples can be effectively studied at the same time [15]. Numerous authors have pointed out that previously indistinguishable hidden bacterial species can also be fully detected in this way $[10,16]$.

With regard to extensive odontogenic abscesses, which require inpatient therapy and can occasionally assume life-threatening dimensions, the following questions therefore arise:

1. Does the oral microbiome of these patients show differences compared to the oral microbiome of healthy patients described in the literature?

2. Which bacteria can be detected in pus using $16 \mathrm{~S}$ rRNA gene next-generation sequencing analysis?

These questions will be addressed in the present study based on patients who were treated for extensive odontogenic abscesses in a University Hospital Department for Oral and Maxillofacial Surgery.

\section{Materials and Methods}

Fifty patients treated for severe odontogenic abscesses between October 2016 and March 2017 in the Department of Oral and Maxillofacial Surgery of the university hospital Giessen and Marburg, Location Giessen, Germany, were included in the study. For the purpose of the study, a saliva sample was taken from the patients prior to the abscess incision in order to determine the oral microbiome. During abscess incision, pus was obtained from the incised abscess. Both samples, saliva and pus, were initially frozen at $-80{ }^{\circ} \mathrm{C}$ for later evaluation. The patients gave their written consent before the study and the study was authorized by the local Ethics Committee of the Medical Faculty of the Justus-Liebig-University Giessen (Vote 191/16).

The determination of the microbiome was carried out around three months after the collection of the last sample with 16S rRNA amplicon sequencing and bioinformatics analysis $[15,17]$. First, bacterial DNA was extracted from the initially frozen pus and saliva. Then, the variable area "V4" of the $16 \mathrm{~S}$ rRNA genes was amplified by polymerase chain reaction (PCR) using primers in the conserved flanking areas with adapters. The resulting amplicons of an approximate length of 350 to 370 base pairs (bps) were processed for 
next-generation sequencing using the Illumina MiSeq System (San Diego, CA, USA). After sequencing, bioinformatics analysis was performed.

\subsection{Nucleic Acid Extraction of Samples, Library Construction, $16 S$ rRNA Amplicon Sequencing}

For nucleic acid extraction, $1 \mathrm{~mL}$ saliva, $0.5 \mathrm{~mL}$ pus and negative controls of water and reaction mixtures were used. To determine the quality of the experiments, a mock community was applied [18].

Samples were centrifuged in $1.5 \mathrm{~mL}$ Eppendorf tubes (13,000 rpm, $10 \mathrm{~min})$. Pellets were resuspended in $150 \mu \mathrm{L}$ lysis buffer $(25 \mathrm{mM}$ Tris, $\mathrm{pH}$ 8.0; $25 \mathrm{mM}$ EDTA, pH $8.0 ; 1 \%$ Triton $\times 100)$. The solution was treated with $20 \mu \mathrm{L}$ Proteinase $\mathrm{K}(20 \mathrm{mg} / \mathrm{mL}$, Ambion, Oberursel, Germany) at $55^{\circ} \mathrm{C}$ for $2 \mathrm{~h}$ and the enzyme was subsequently inactivated at $90{ }^{\circ} \mathrm{C}$ for $30 \mathrm{~min}$. After further incubation with $50 \mu \mathrm{L}$ lysozyme $(20 \mathrm{mg} / \mathrm{mL}$, Merck, Darmstadt, Germany), $10 \mu \mathrm{L}$ lysostaphin (5 U/ $\mu \mathrm{L}$, Sigma, St. Louis, MO, USA) and $10 \mu \mathrm{L}$ mutanolysin $\left(5 \mathrm{U} / \mu \mathrm{L}\right.$, Sigma, St. Louis, MO, USA) at $37^{\circ} \mathrm{C}$ for $30 \mathrm{~min}, \mathrm{DNA}$ was extracted by using glass beads and the Power Lyzer DNA Isolation Kit from MoBio as recommended by the vendor (MoBio Laboratories, Carlsbad, CA, USA). DNA of all samples was eluted in $100 \mu \mathrm{L}$ of nuclease-free water and concentration was determined using Qubit Fluorometric Quantitation (Thermo Fisher Scientific, Waltham, MA, USA). The V4 region of $16 \mathrm{~S}$ rRNA gene was amplified using adapter forward primer $5^{\prime}-$ TCGTCGGCAGCGTCAGATGTGTATAAGAGACAGGTGCCAGCMGCCGCGGTAA-3' , and adapter reverse primer 5'-GTCTCGTGGGCTCGGAGATGTGTATAAGAGACAGGGTACH VGGGTWTCTAAT-3' and the 2× Kapa HiFi HotStart Ready Mix (Kapa Biosystems, Wilmington, MA, USA). Amplification profile comprised an initial heating step at $95^{\circ} \mathrm{C}$ for $3 \mathrm{~min}$, 25 cycles of denaturation at $95^{\circ} \mathrm{C}$ for $30 \mathrm{~s}$, annealing at $55^{\circ} \mathrm{C}$ for $30 \mathrm{~s}$, elongation at $72{ }^{\circ} \mathrm{C}$ for $30 \mathrm{~s}$ and a final elongation step at $72{ }^{\circ} \mathrm{C}$ for $5 \mathrm{~min}$. PCR products were purified with Agencourt AMPure XP system as recommended by the vendor (Beckman Coulter, Brea, CA, USA). Size, purity and concentration of amplicons were determined using the Agilent Bioanalyzer as recommended by the vendor (Agilent Technologies, Santa Clara, CA, USA). The index PCR was performed using the Nextera index Kit v2 Set B as recommended by the vendor (Illumina, San Diego, CA, USA). The quality of the index PCR was determined as described above for the adapter PCR. The library was adjusted to $3 \mathrm{pM}$, and the flow cell was prepared and loaded according to the Reagent Preparation Guide of MiSeq Reagent Kit v2 and sequenced as recommended by the vendor (Illumina).

\subsection{Bioinformatics Analysis}

Microbiome analysis was performed as previously described [19]. In brief, paired end sequence reads were joined and primer sequences were removed. Saliva sequence reads varied between 8465 and 309,076 and pus reads varied between 28,698 and 751,847 per sample. Reads with ambiguous base calls or with homopolymers longer than eight nucleotides were removed and duplicates were merged and aligned against the SILVAbases bacterial reference alignment [20]. Applying Mothur implementation of the uchime algorithm, chimeric reads were removed, taxonomy was assigned and non-bacterial reads were removed from the analysis. Operational taxonomic units (OTU) were generated and taxonomy was reassigned using Mothur. In preparation for the analysis, an OTU table in biom format was created.

\subsection{Statistical Analysis}

Statistical analysis was carried out with Microsoft Excel (Redmond, WA, USA) and the statistical software R-4.0.4 (R Core Team, 2021, Vienna, Austria). For calculation of frequencies, we considered a phylotype to be abundant if it contributed to at least $0.01 \%$ of the microbiome. Lilliefors (Kolmogorov-Smirnov) test ( $\mathrm{R}$ package: nortest) was applied to test for normality distribution. In addition, histograms were used to visualize alpha-diversity in the saliva and pus samples. To describe the composition of the microbiomes, means, standard deviations and medians of the relative frequencies of the 
reads were detected and shown in a table and in pie charts. Thus, a median microbiome was calculated for saliva and pus samples to show the median composition of the saliva and pus microbiomes. Alpha diversity was further illustrated with heatmaps directly contrasting the relative frequencies of reads in saliva and pus. Hierarchical clustering (method: ward with Euclidean distance) and principal component analysis (PCA) were used to describe beta diversity among the saliva and pus samples. Heatmaps, hierarchical clustering and PCA were based on the relative frequency of the reads of the most frequent bacterial genera (sum of rows $>20 \%$ ). This means that the sum of the relative abundances in a row of the heatmaps must be more than $20 \%$ for the corresponding bacterial genus to be displayed.

Heatmaps and hierarchical clustering were performed by the R package pheatmap, and PCA was visualized by biplots using the R package ggfortify.

\section{Results}

In the observation period from October 2016 to March 2017, a total of 50 patients with a severe odontogenic abscess were treated with incision and drainage at the University Hospital. In addition to the normal microbiological standard examination (microbiological smear and culture), a sample of saliva and drained pus was obtained from all 50 patients. Among them, 34 patients $(68 \%)$ were male and 16 patients $(32 \%)$ were female. The mean age was 47.42 years (standard deviation: 19.59 years). The Lilliefors test showed that the distribution of the patients' age did not differ significantly from that which was normally distributed $(p=0.415)$. The most frequently observed abscesses were perimandibular and submandibular, occurring in 15 patients (30\%) each. Figure 1 shows the frequency of the observed abscesses.

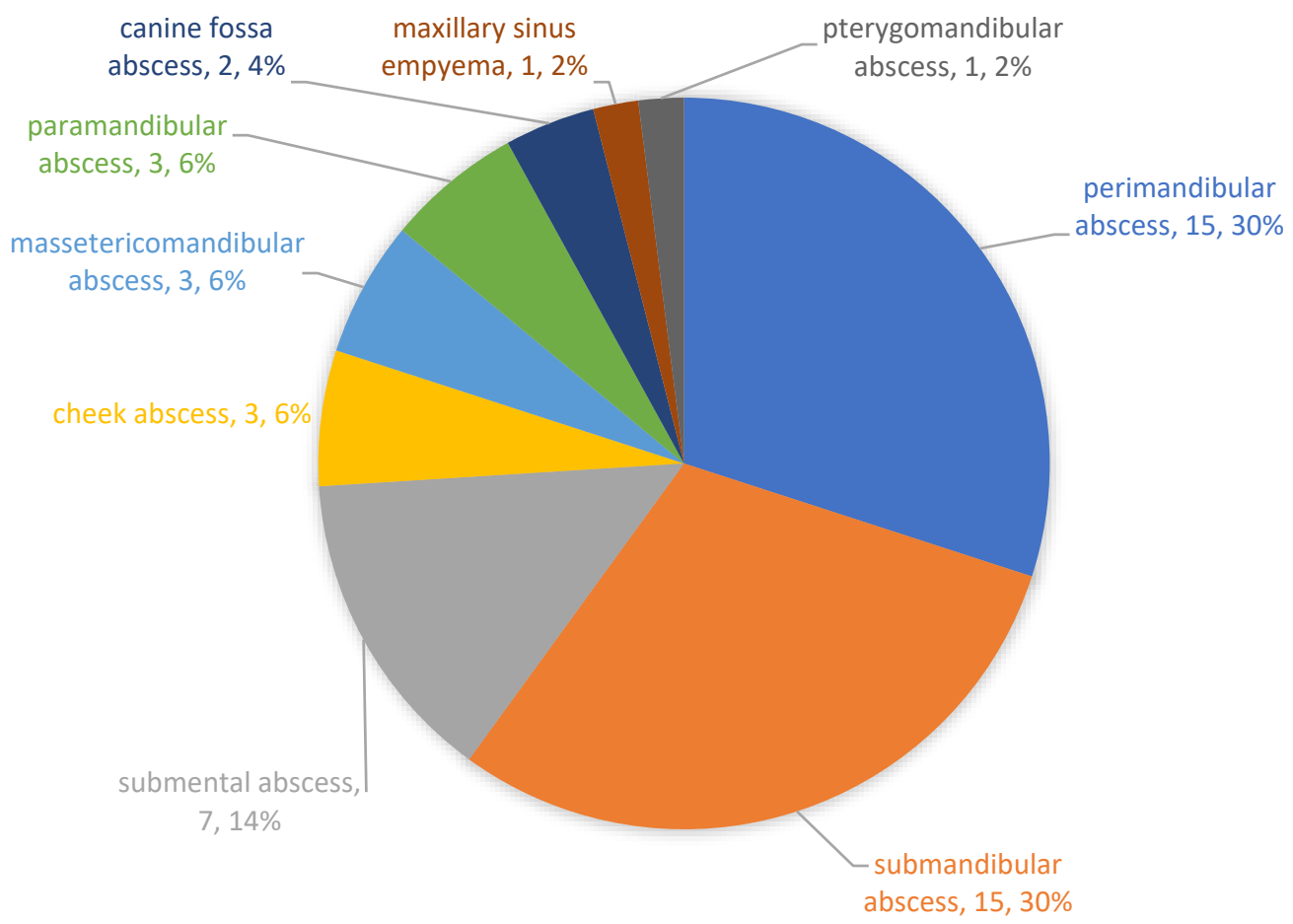

Figure 1. Frequency of the observed abscesses. The most common abscesses were the perimandibular and the submandibular abscess.

Furthermore, 16S rRNA gene analysis revealed the microbiome of the saliva and the drained pus. As in other studies, an abundance of bacterial genera was found, both in saliva and pus. We considered a phylotype to be abundant if it contributed to at least $0.01 \%$ of the microbiome. Using this threshold, a mean of $41.32( \pm 9.00)$ bacterial genera was found in the saliva and a mean of $31.44( \pm 12.09)$ was found in the pus. Figure 2 shows the 
distribution of the counted bacterial genera in the saliva and the pus. The Lilliefors test showed that the distribution of the number of bacterial genera did not differ significantly from that which was normally distributed (saliva: $p=0.303$ and pus: $p=0.321$ ). The two-tailed paired-samples $t$-test for means showed that the number of bacterial genera was significantly higher in the saliva than in the pus $(p<0.0001)$.
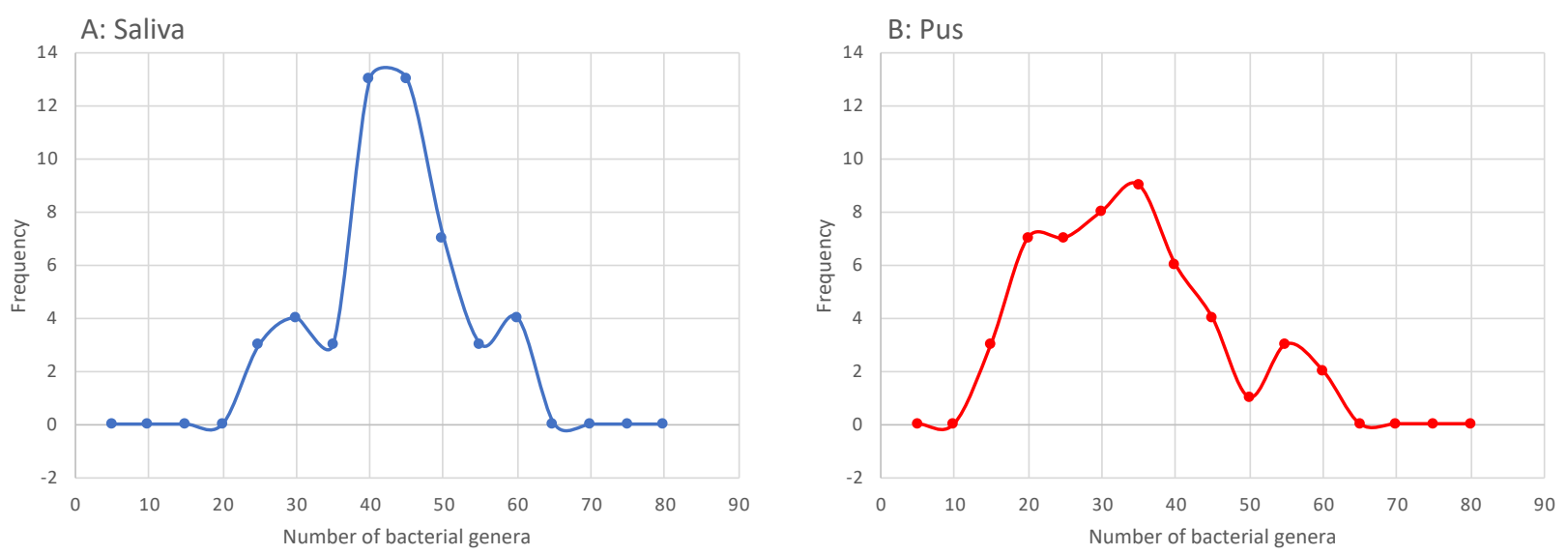

Figure 2. Histogram of the counted bacterial genera in the saliva (A) and the pus (B) to describe alpha diversity. The occurrence of a genus was counted if the genus contributed to at least $0.01 \%$ of the microbiome.

Despite the high number of different bacteria even in the pus samples, we found a clear predominance of one genus, namely Streptococcus, in two of the $50(4 \%)$ cases. One of these cases is presented in Figure 3. The microbiomes found in the pus of these patients presumably correspond to a bacterial mono-infection with Streptococcus, while all other microbiomes of the pus showed the typical picture of a polymicrobial infection without a predominance of a specific genus. Figure 4 outlines a case of a typical polymicrobial infection. Thus, a polymicrobial infection could be observed in 48 of 50 cases (96\%). 


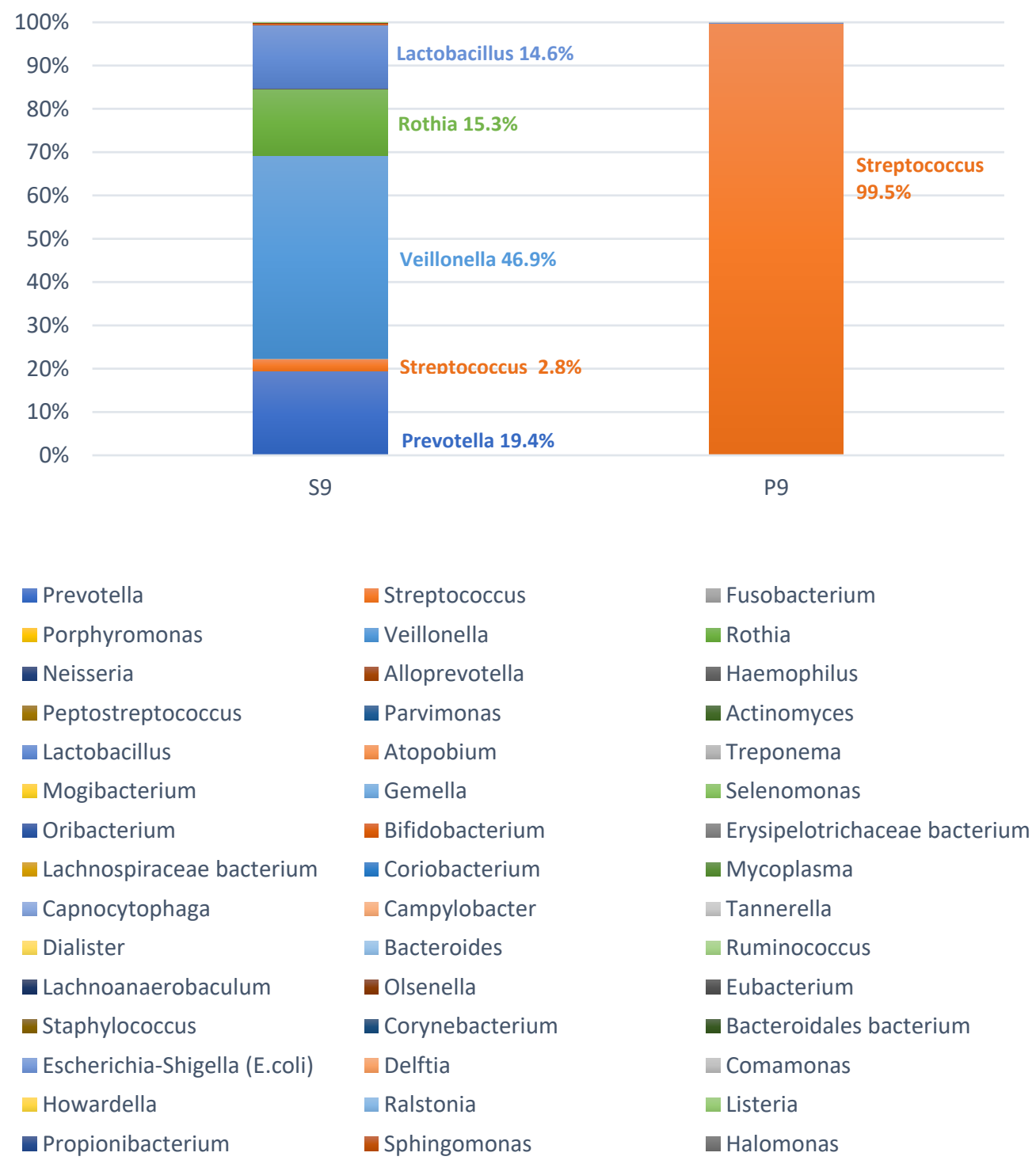

Figure 3. Microbiome of the saliva (S9) and the pus (P9) of patient no. 9. Herein, $99.5 \%$ of the reads belong to the genus Streptococcus and thus show the picture of a mono-infection. The legend contains all detected bacterial genera of the two related samples. The order in the legend corresponds to the total abundance in saliva and pus of all 50 samples (decreasing from left to right). 


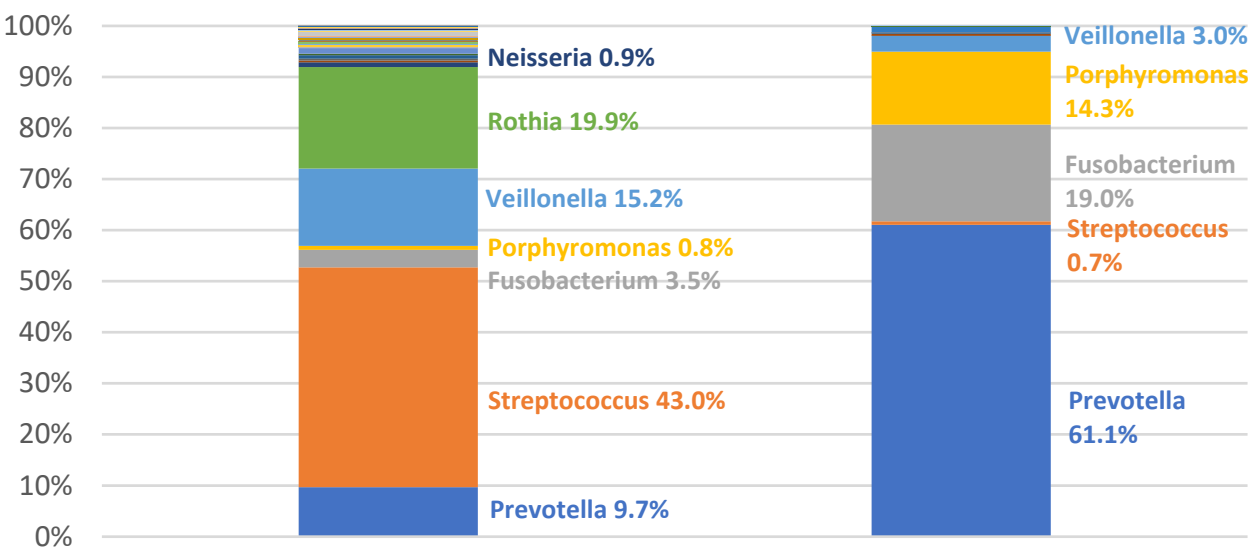

S2

P2

- Prevotella
Porphyromonas
- Neisseria
- Peptostreptococcus
- Lactobacillus
Mogibacterium
- Slackia
Bifidobacterium
Coriobacterium
Campylobacter
Dialister
- Lachnoanaerobaculum
Catonella
Corynebacterium
- Anaerococcus
Methylophilus
Oxalobacter
Cardiobacterium
Xanthomonas
Micrococcus

Streptococcus
Veillonella
Alloprevotella
- Parvimonas
Atopobium
Filifactor
Oribacterium
Erysipelotrichaceae bacterium
Mycoplasma
Fretibacterium
Bacteroides
Olsenella
Staphylococcus
Escherichia-Shigella (E.coli)
Comamonas
Peptoniphilus
Rhizobium
$\square$ Listeria
Brevibacterium
Microbacterium

Fusobacterium Rothia

- Haemophilus

- Actinomyces

- Treponema

- Selenomonas

- Leptotrichia

Figure 4. Microbiome of the saliva (S2) and the pus (P2) of patient no. 2. The microbiome of the pus shows the typical picture of a polymicrobial infection. The legend contains all detected bacterial genera of the two related samples. The order in the legend corresponds to the total abundance in saliva and pus of all 50 samples (decreasing from left to right).

In order to show the composition of the microbiomes, Table 1 lists the 50 most frequently detected bacterial genera of the saliva and the pus samples. Since no normal distribution can be assumed for the relative frequencies of the reads, the median can be considered a more suitable measure than the arithmetic mean. Thus, Figures 5 and 6 show the median composition of the saliva and pus microbiomes. It can be clearly seen that the compositions of the microbiomes differ. In particular, the genera Porphyromonas and Fusobacterium are more common in the pus, while the genus Streptococcus is less abundant in the pus. Despite the two described mono-infections with Streptococcus, the median relative frequency of the DNA from this genus was only $1.15 \%$ in pus. 
Table 1. Relative frequencies in percent of the 50 most frequently detected bacterial genera in the saliva and pus samples, sorted in descending order according to the mean value. It is obvious that the median deviates often from the mean and thus a normal distribution of the data cannot be assumed. The column "S.dev." represents the standard deviation and the column "MM" extrapolates the median to $100 \%$ and indicates what percentage of a saliva or pus sample can be assigned to a corresponding bacterial genus.

\begin{tabular}{|c|c|c|c|c|c|c|c|c|c|}
\hline Genus (Saliva Samples) & Mean & S.dev & Median & MM & Genus (Pus Samples) & Mean & S.dev. & Median & MM \\
\hline Prevotella & 17.65 & 13.95 & 16.39 & 26.67 & Prevotella & 27.12 & 17.00 & 27.91 & 48.76 \\
\hline Streptococcus & 17.26 & 13.85 & 14.95 & 24.34 & Fusobacterium & 16.03 & 18.92 & 9.13 & 15.95 \\
\hline Veillonella & 9.33 & 8.63 & 6.67 & 10.85 & Porphyromonas & 12.94 & 13.95 & 11.26 & 19.67 \\
\hline Rothia & 8.43 & 11.95 & 4.40 & 7.16 & Streptococcus & 6.57 & 20.07 & 1.15 & 2.00 \\
\hline Neisseria & 7.18 & 10.99 & 2.87 & 4.68 & Peptostreptococcus & 4.91 & 6.97 & 0.17 & 0.30 \\
\hline Haemophilus & 5.85 & 8.47 & 2.25 & 3.66 & Parvimonas & 4.79 & 6.58 & 2.16 & 3.78 \\
\hline Actinomyces & 4.39 & 3.41 & 3.99 & 6.50 & Veillonella & 3.31 & 3.28 & 2.83 & 4.95 \\
\hline Alloprevotella & 4.14 & 8.01 & 0.86 & 1.39 & Alloprevotella & 2.36 & 5.14 & 0.42 & 0.74 \\
\hline Lactobacillus & 4.10 & 6.02 & 1.94 & 3.16 & Mogibacterium & 1.45 & 1.78 & 1.02 & 1.79 \\
\hline Porphyromonas & 2.63 & 4.72 & 0.90 & 1.47 & Filifactor & 1.36 & 2.17 & 0.47 & 0.82 \\
\hline Fusobacterium & 2.35 & 2.91 & 1.47 & 2.39 & Atopobium & 1.32 & 2.09 & 0.14 & 0.24 \\
\hline Atopobium & 2.23 & 2.58 & 1.32 & 2.15 & Erysipelothrix & 1.28 & 3.26 & 0.00 & 0.00 \\
\hline Gemella & 1.28 & 2.05 & 0.45 & 0.73 & Slackia & 1.24 & 1.86 & 0.24 & 0.42 \\
\hline Leptotrichia & 1.14 & 1.34 & 0.42 & 0.69 & Treponema & 1.18 & 3.10 & 0.05 & 0.08 \\
\hline Bifidobacterium & 1.09 & 1.97 & 0.23 & 0.37 & Oribacterium & 0.99 & 2.70 & 0.02 & 0.03 \\
\hline Peptostreptococcus & 0.93 & 1.64 & 0.14 & 0.24 & Lachnospira & 0.96 & 2.34 & 0.00 & 0.00 \\
\hline Capnocytophaga & 0.92 & 1.46 & 0.24 & 0.39 & $\begin{array}{c}\text { Erysipelotrichaceae } \\
\text { bacterium }\end{array}$ & 0.85 & 2.03 & 0.00 & 0.00 \\
\hline Treponema & 0.83 & 1.96 & 0.22 & 0.35 & Selenomonas & 0.82 & 4.37 & 0.01 & 0.02 \\
\hline Selenomonas & 0.71 & 1.03 & 0.29 & 0.48 & Coriobacterium & 0.79 & 2.36 & 0.06 & 0.10 \\
\hline Mogibacterium & 0.55 & 0.96 & 0.19 & 0.31 & Family_XIII_ge & 0.74 & 1.33 & 0.00 & 0.00 \\
\hline Parvimonas & 0.50 & 0.93 & 0.12 & 0.20 & Mycoplasma & 0.71 & 2.21 & 0.00 & 0.01 \\
\hline Oribacterium & 0.49 & 0.65 & 0.18 & 0.29 & $\begin{array}{c}\text { Lachnospiraceae } \\
\text { bacterium }\end{array}$ & 0.66 & 1.61 & 0.00 & 0.00 \\
\hline Campylobacter & 0.46 & 0.49 & 0.34 & 0.55 & Fretibacterium & 0.51 & 2.16 & 0.01 & 0.01 \\
\hline Erysipelothrix & 0.42 & 0.80 & 0.00 & 0.00 & Gemella & 0.48 & 1.42 & 0.01 & 0.01 \\
\hline Lachnospira & 0.41 & 0.90 & 0.00 & 0.00 & Bacteroides & 0.47 & 2.80 & 0.00 & 0.00 \\
\hline Lachnoanaerobaculum & 0.37 & 0.66 & 0.08 & 0.12 & Pyramidobacter & 0.46 & 2.24 & 0.00 & 0.00 \\
\hline Lachnospiraceae bacterium & 0.36 & 0.89 & 0.01 & 0.01 & Dialister & 0.41 & 0.89 & 0.04 & 0.08 \\
\hline Pasteurella & 0.30 & 0.88 & 0.00 & 0.00 & Tannerella & 0.33 & 0.84 & 0.00 & 0.01 \\
\hline Mycoplasma & 0.29 & 0.67 & 0.04 & 0.06 & Campylobacter & 0.31 & 0.70 & 0.02 & 0.04 \\
\hline Slackia & 0.25 & 0.45 & 0.08 & 0.14 & Neisseria & 0.31 & 0.75 & 0.01 & 0.01 \\
\hline $\begin{array}{c}\text { Erysipelotrichaceae } \\
\text { bacterium }\end{array}$ & 0.24 & 0.53 & 0.00 & 0.00 & Ruminococcus & 0.30 & 1.37 & 0.00 & 0.00 \\
\hline Filifactor & 0.24 & 0.46 & 0.02 & 0.04 & Eubacterium & 0.29 & 0.51 & 0.01 & 0.01 \\
\hline Fretibacterium & 0.24 & 0.44 & 0.06 & 0.10 & Haemophilus & 0.28 & 0.80 & 0.01 & 0.01 \\
\hline Tannerella & 0.23 & 0.36 & 0.08 & 0.13 & Actinomyces & 0.25 & 1.21 & 0.01 & 0.02 \\
\hline Family_XIII_ge & 0.23 & 0.49 & 0.00 & 0.00 & Catonella & 0.21 & 0.58 & 0.03 & 0.06 \\
\hline Coriobacterium & 0.21 & 0.35 & 0.09 & 0.14 & Olsenella & 0.20 & 0.64 & 0.00 & 0.00 \\
\hline Olsenella & 0.17 & 0.42 & 0.03 & 0.06 & Rikenella & 0.19 & 0.41 & 0.00 & 0.01 \\
\hline Dialister & 0.14 & 0.28 & 0.04 & 0.07 & Staphylococcus & 0.18 & 0.79 & 0.01 & 0.02 \\
\hline Ruminococcus & 0.13 & 0.27 & 0.02 & 0.03 & Clostridium & 0.17 & 0.73 & 0.00 & 0.00 \\
\hline Desulfovibrio & 0.09 & 0.27 & 0.00 & 0.00 & Acidaminococcus & 0.16 & 0.79 & 0.00 & 0.00 \\
\hline Escherichia-Shigella (E.coli) & 0.09 & 0.48 & 0.00 & 0.00 & Clostridiales bacterium & 0.16 & 0.52 & 0.00 & 0.00 \\
\hline SR1_(Absconditabacteria)_ge & 0.09 & 0.37 & 0.00 & 0.00 & Bacteroidales_S24-7 & 0.16 & 1.00 & 0.00 & 0.00 \\
\hline Corynebacterium & 0.08 & 0.15 & 0.03 & 0.05 & Peptococcus & 0.13 & 0.38 & 0.00 & 0.00 \\
\hline Catonella & 0.08 & 0.14 & 0.02 & 0.04 & Rothia & 0.12 & 0.36 & 0.01 & 0.02 \\
\hline Bacteroides & 0.07 & 0.38 & 0.00 & 0.00 & Stenotrophomonas & 0.12 & 0.82 & 0.00 & 0.00 \\
\hline Mollicutes & 0.07 & 0.21 & 0.00 & 0.00 & Lactobacillus & 0.12 & 0.31 & 0.02 & 0.03 \\
\hline Sphaerochaeta & 0.07 & 0.36 & 0.00 & 0.00 & Desulfovibrio & 0.11 & 0.55 & 0.00 & 0.00 \\
\hline Rikenella & 0.07 & 0.15 & 0.01 & 0.01 & Delftia & 0.09 & 0.41 & 0.00 & 0.01 \\
\hline Peptococcus & 0.05 & 0.10 & 0.00 & 0.00 & Bacteroidales bacterium & 0.08 & 0.44 & 0.00 & 0.00 \\
\hline Flavobacterium & 0.04 & 0.08 & 0.00 & 0.00 & Pasteurella & 0.07 & 0.36 & 0.00 & 0.00 \\
\hline
\end{tabular}




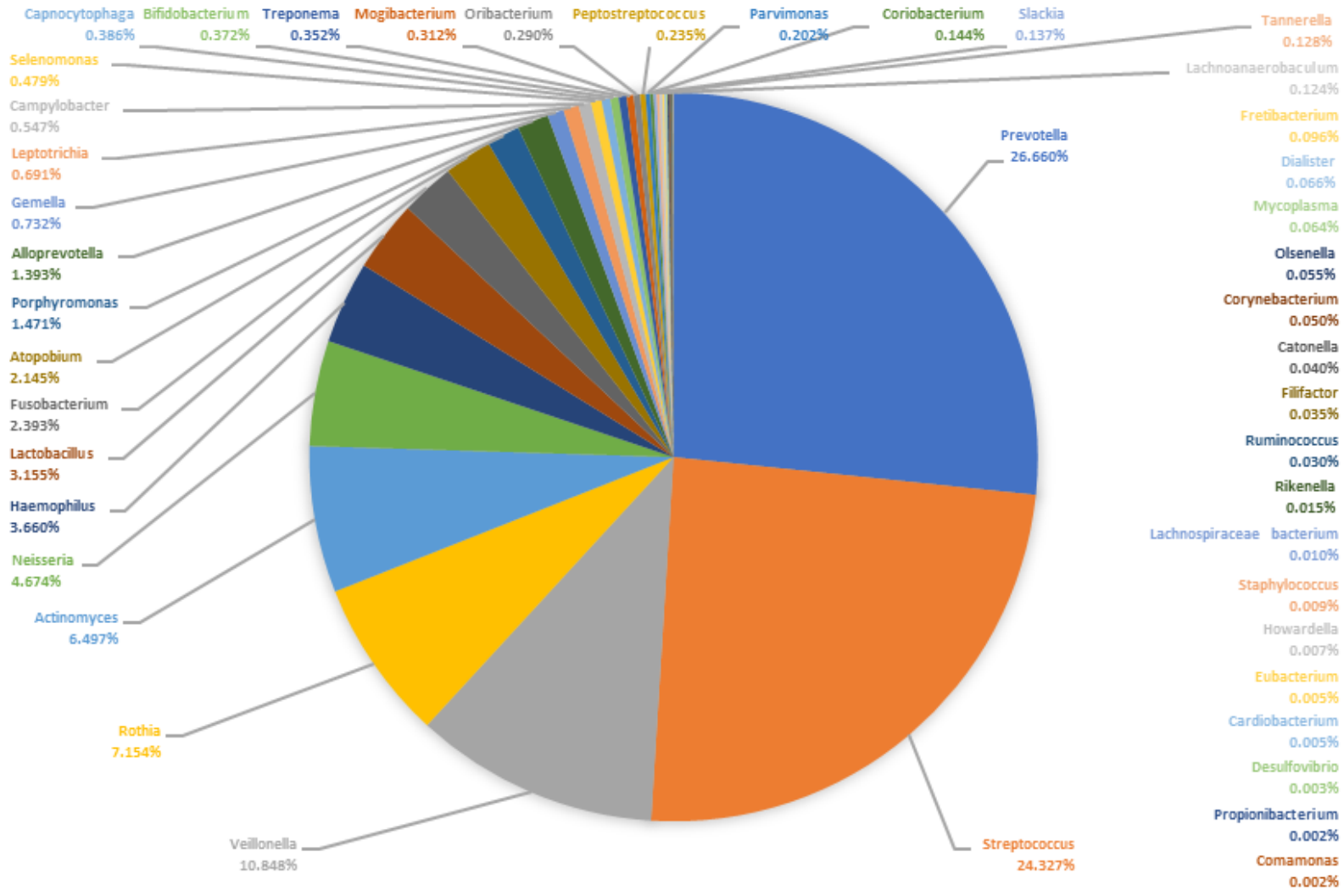

Figure 5. Median microbiome of all saliva samples $(n=50)$. The pie chart shows the proportion of the bacterial genera of the sum of all medians of the relative abundances.

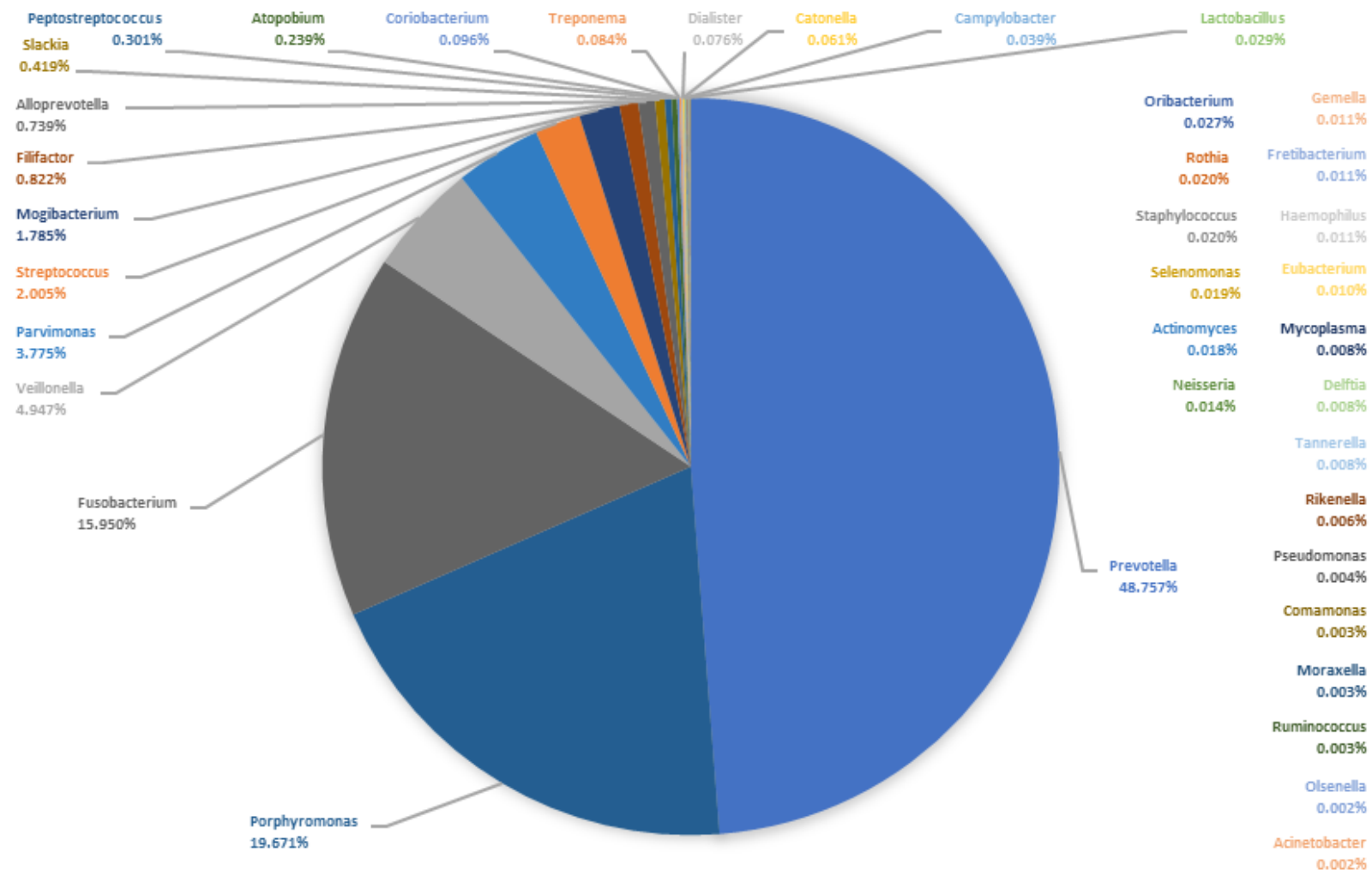

Figure 6. Median microbiome of all pus samples $(n=50)$. The pie chart shows the proportion of the bacterial genera of the sum of all medians of the relative abundances. 
To describe the composition of the microbiomes in more detail, Figure 7 shows a heatmap of the saliva and pus samples, where the different samples are separated in terms of content (saliva samples on the left side and pus samples on the right side).

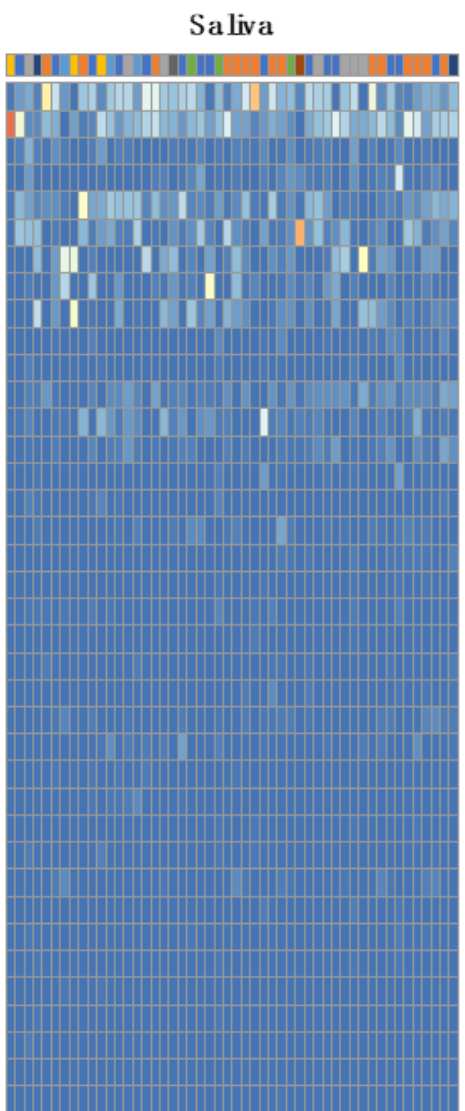

Saliva-samples (S1-S56)
Pus

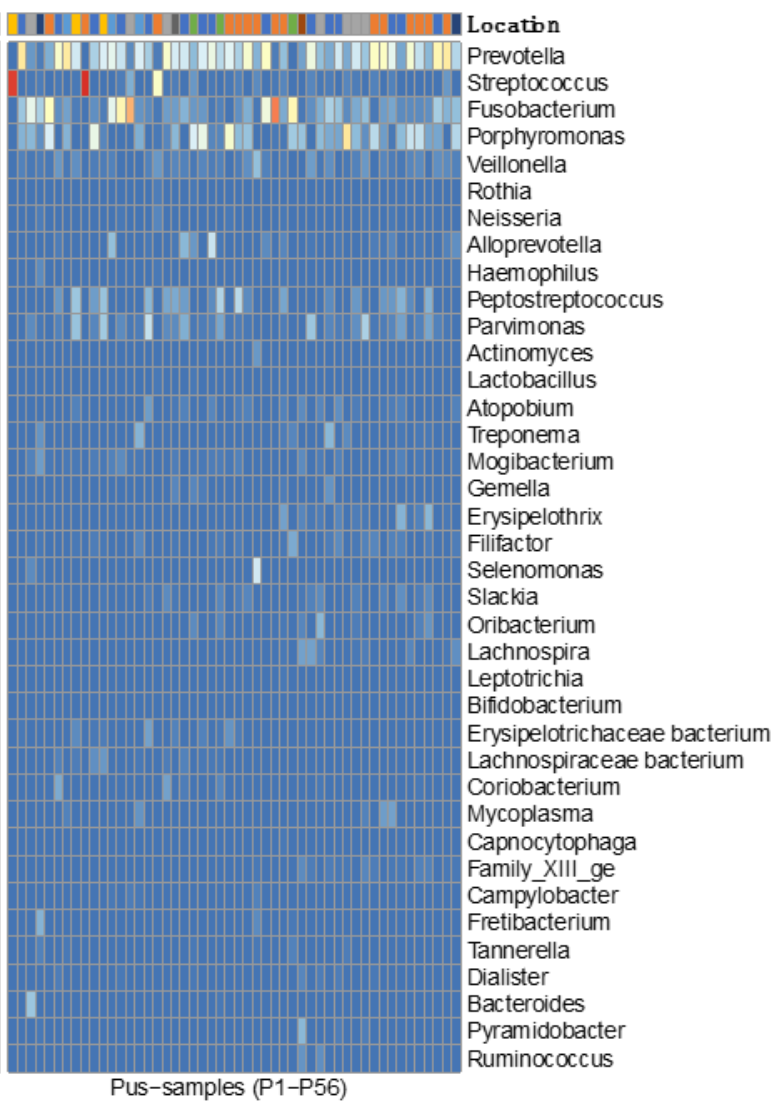

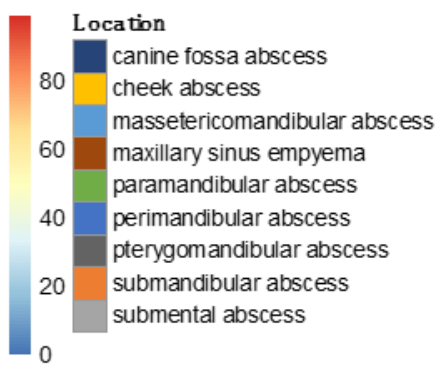

0

Figure 7. Heatmap of all saliva and pus samples $(n=100)$. Colors show the relative frequencies (sum of rows $>20 \%$ ). Saliva samples are shown on the left side and pus samples on the right side. It is obvious that the abundance of Porphyromonas and Fusobacterium is greater in pus while the abundance of Streptococcus is greater in saliva.

Figure 8 shows the corresponding heatmap in which the saliva and pus samples are subjected to hierarchical clustering. It is clearly visible that the algorithm separates the samples almost completely due to the different compositions of the samples. It can also be seen that the abscess location has no influence on the composition of the microbiome. Figure 9 shows this clearly using principal component analysis for the bacteria listed in the heatmap. It is clearly recognizable that the saliva samples are separated from the pus samples, showing the predominant bacteria in saliva at the bottom right and the predominant bacteria in pus at the top left, according to the median microbiomes of saliva and pus (Figures 5 and 6). 


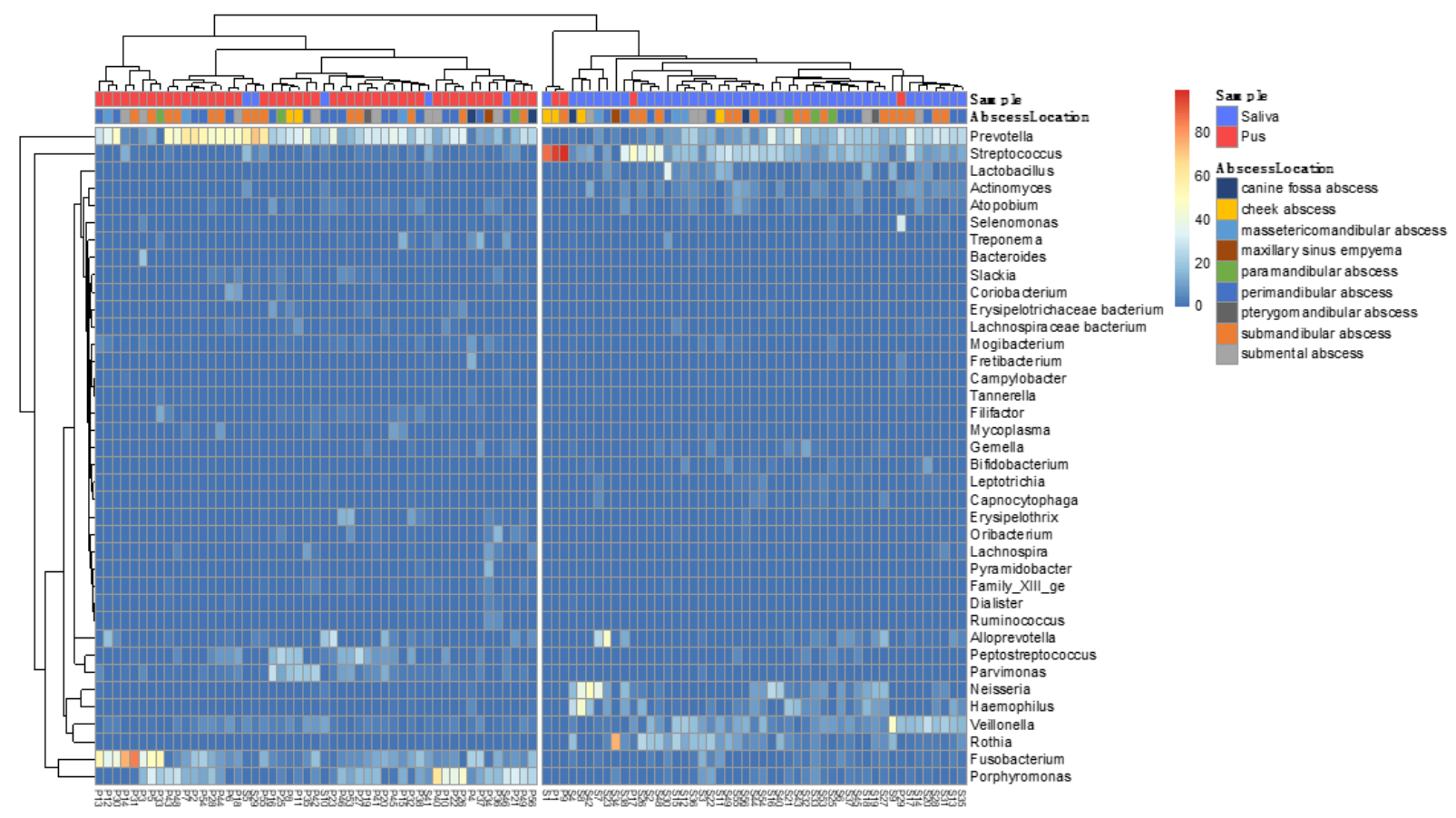

Figure 8. Heatmap of all saliva and pus samples $(n=100)$. Colors show the relative frequency of the reads of the most frequent bacterial genera (sum of rows $>20 \%$ ). Hierarchical clustering with dendrogram (method: ward with Euclidean distance). It is demonstrated that the samples are almost completely separated by clustering, indicating the different compositions of the samples. The heatmap also shows that abscess location has no significant influence on the composition of the microbiome.

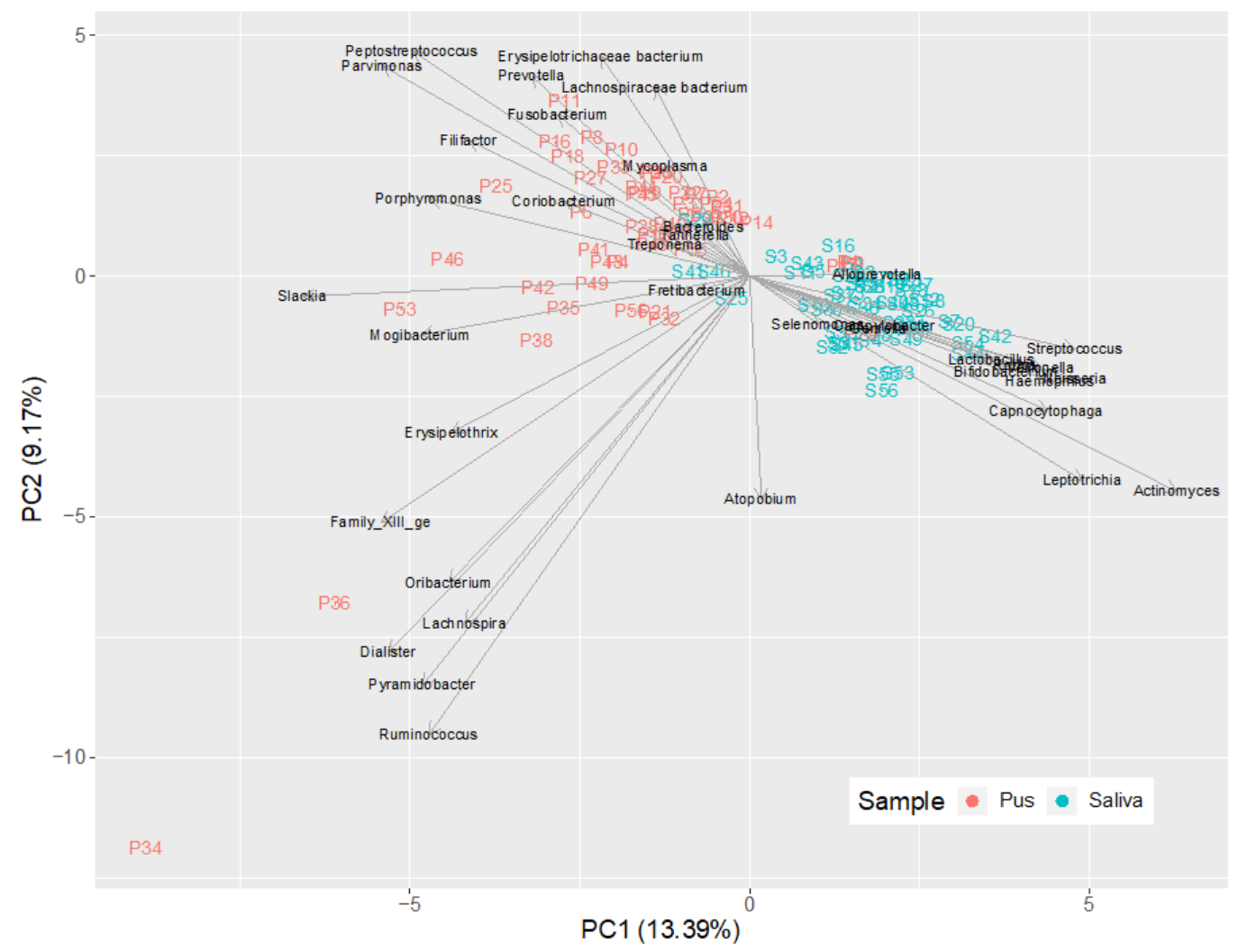

Figure 9. Principal component analysis biplot of all saliva and pus samples ( $n=100$; sum of rows $>20 \%)$ in order to visualize the relationship between the bacterial genera and the distances between samples (beta diversity). As can be seen, there is almost a complete separation of the samples (saliva and pus). 
Figure 10 displays the oxygen metabolism of the bacteria in the pus and the saliva according to the median microbiome. It is obvious that the pus group contained predominantly anaerobic bacteria, while, in saliva, around half of the bacteria were aerobic and facultative anaerobic.
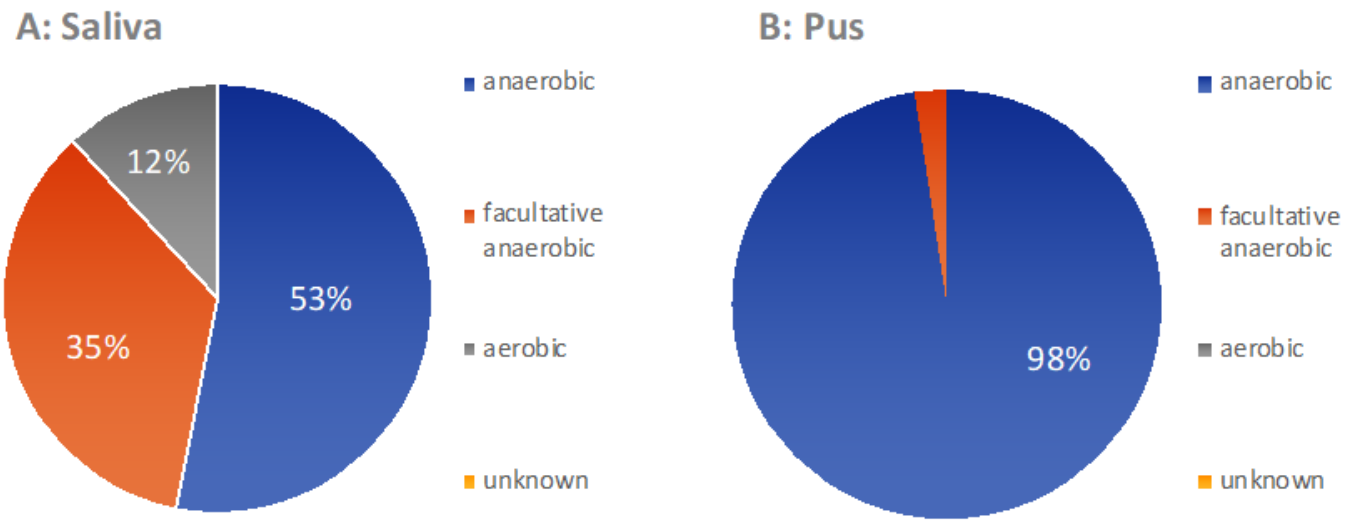

Figure 10. Median metabolism of the saliva samples $(\mathbf{A})$ and the pus samples $(\mathbf{B})(n=50)$. There is a clear increase in the proportion of anaerobic bacteria in the abscess.

Regarding the median microbiome of the pus, Prevotella, Porphyromonas and Fusobacterium were especially predominant. Individual species of these genera have been described as highly periodontally pathogenic by numerous authors. Thus, Socransky et al. defined bacterial complexes that are supposed to express different degrees of pathogenicity by means of color [21]. In particular, bacteria that can be assigned to the orange and red complexes indicate strong pathogenicity. With the underlying 16S rRNA gene analysis, the bacteria can only be identified down to the level of the genus, so that a definitive classification cannot be made here. However, Figure 11 attempts to outline a potential affiliation with the orange and the red complex in particular. For the genera with no relationship to the complexes and the genus Streptococcus (otherwise "the yellow complex"), the natural habitat of the bacteria is indicated, such as "gut" or "oral cavity". Considering the results, a possible affiliation to the orange or red complex is observed clearly more frequently in pus than in saliva. It can therefore be assumed that the pathogenic potential of the bacteria identified in pus is significantly higher than in saliva.
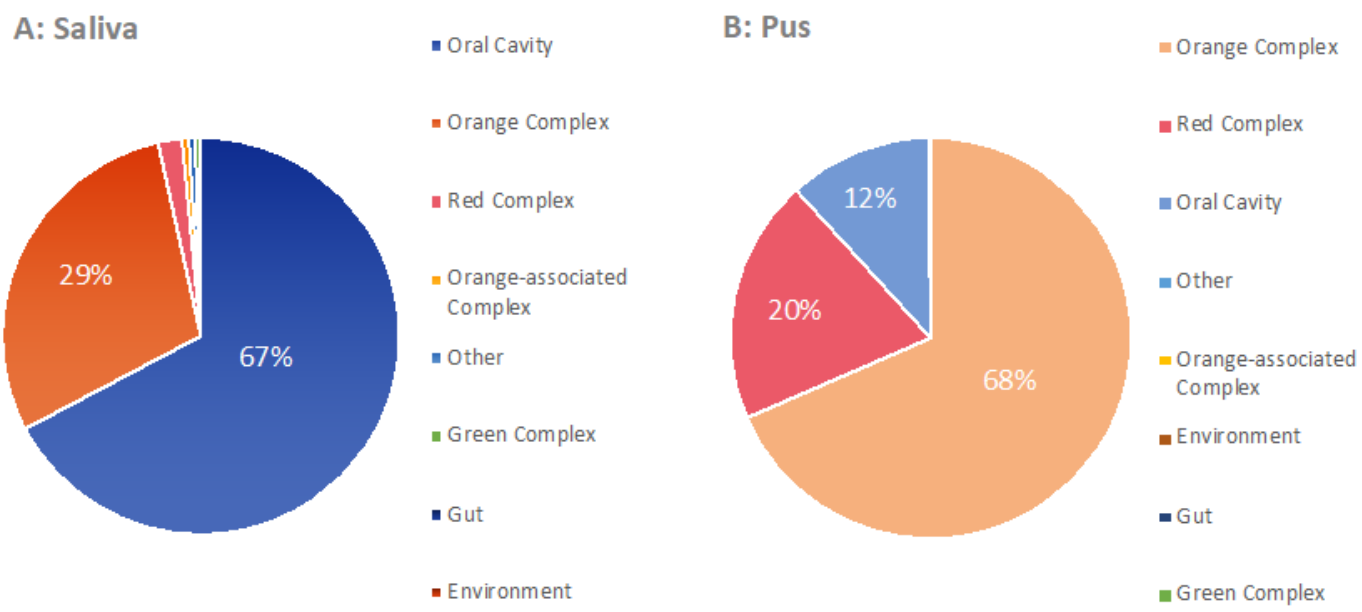

Figure 11. Classification of the median microbiomes ((A) saliva (B) pus) according to the complexes described by SocranScheme 50. [21]. Bacteria of the red and orange complex are associated with strong pathogenicity in periodontal disease. The genus Streptococcus (otherwise yellow complex) was assigned to the "oral cavity" group in this representation. 
Finally, the phylum affiliation of the individual bacterial genera in saliva and pus was determined (Figure 12). In saliva, the results were comparable to those of other investigations [10]. In the pus, the result was also comparable to other studies [3] but with a much clearer predominance of Bacteroidetes.
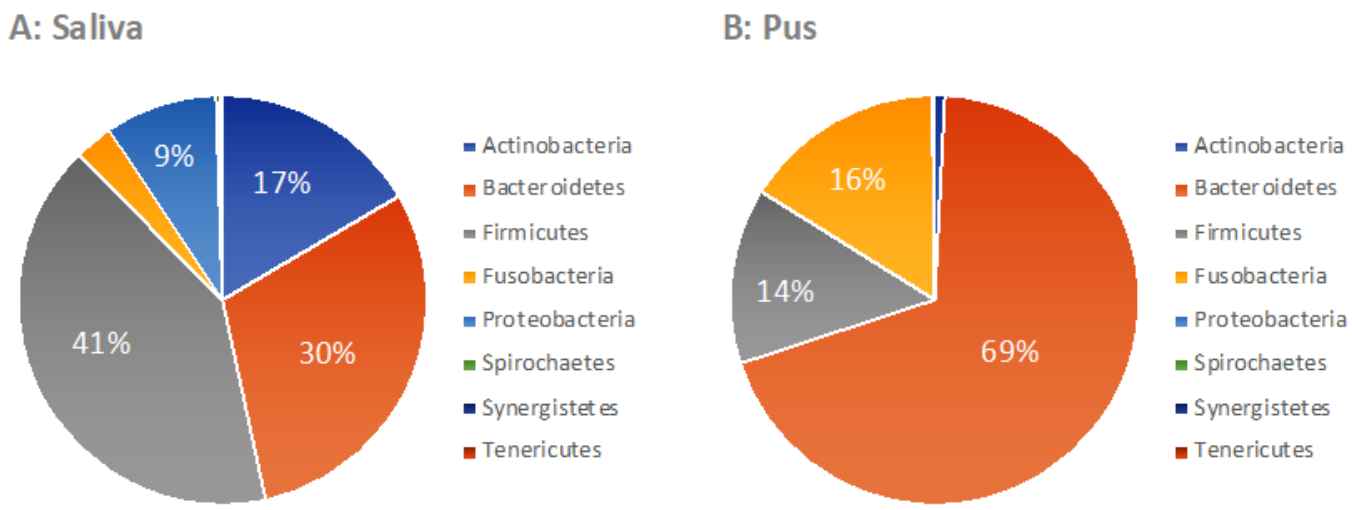

Figure 12. Phylum-level diversity of the oral microbiome $(\mathbf{A})$ and the pus microbiome $(\mathbf{B})(n=50)$.

\section{Discussion}

Acute odontogenous abscesses are among the most common inflammatory diseases in the head and neck region. Most abscesses are localized and can be successfully treated by local incision from the mouth using local anesthesia [3].

Larger abscesses often show a tendency to spread and are usually incised extraorally using general anesthesia [1]. These abscesses can cause severe local and systemic complications and even lead to death [1-3]. Local complications are osteomyelitis and sinusitis and systemic complications include sepsis, endocarditis, spondylitis, orbital phlegmon, orbital abscess, necrotizing fasciitis, brain abscess, mediastinitis and adult respiratory distress syndrome [1,3]. Rapid and efficient diagnosis and therapy is therefore of great importance, especially in advanced diseases. In addition to adequate imaging, the determination of the microorganisms present in the abscess is of particular importance.

\subsection{Culture-Based versus Molecular Detection Methods}

Traditionally, culture methods have been used for bacterial detection, which have provided a considerable amount of information on bacterial etiology and the species involved in odontogenic abscesses [3]. Nevertheless, the sole detection of bacteria by means of culture does not seem to provide a fully comprehensive picture of the actually present bacterial spectrum [3]. In order to successfully culture oral bacteria in the laboratory, the culture media must be adapted to their specific variable requirements [12,22]. Since odontogenic abscesses are usually polymicrobial in composition [3], it can be difficult to provide a culture environment that is equally suitable for all relevant bacteria. In addition, bacterial detection may also be incorrect or incomplete due to inadequate transport conditions or delayed start of culture [3]. Early microscopic studies already discussed that the actual number of bacteria in the mouth is probably significantly higher than the number of bacteria that can actually be detected by culture [23]. The introduction of culture-independent molecular biological methods into the analysis of oral bacterial diversity has not only confirmed this picture conveyed by microscopic studies, but also revealed an even broader and more diverse spectrum of oral bacteria [14]. In 2013, Siquera and Rôças described in their review that $40 \%$ to $70 \%$ of oral bacterial species have not yet been cultivated and phenotypically characterized [3]. To date, a lack of essential nutrients or growth factors in the culture, overfeeding conditions during culture, toxicity of the culture medium itself, inhibition by other microorganisms in the sample and metabolic dependence on other microorganisms have been suggested as possible reasons for the failure of culture-based detection [3]. It is therefore not surprising that only a few species 
have been described as causative pathogens, especially in culture-based studies on the microbial spectrum of odontogenic abscesses [24-30]. The review by Siquera and Rôças, for example, reported an average of only 3.3 to 8.5 identified species per abscess using culture-based methods, whereas 77 to 114 genera or species per abscess were found using next-generation sequencing [3]. Despite the widely publicized importance of emergent communities and symbioses [21], the search is ongoing for the "triggering species" to treat effectively with an antibiogram [3]. Numerous authors have demonstrated that endodontic infections such as other endogenous infections are not due to a single bacterial species but usually due to a community of species [31-33]. The search for a causative pathogen with the aim of a suitable antibiotic therapy according to an antibiogram therefore appears to be difficult in odontogenic infections.

\subsection{Microbiome of the Saliva}

The aim of this study was to determine the oral microbiome in saliva and the microbiome of the pus of abscesses, respectively, in patients with extensive odontogenic infections using $16 \mathrm{~S}$ rRNA gene analysis, next-generation sequencing and bioinformatics. For this purpose, a saliva sample was obtained prior to incision of the abscess and a pus sample was harvested during the incision and evaluated beyond normal clinical routine. The examination of the oral microbiome from the saliva samples revealed findings comparable to other examinations [10,34-36]. In the review of Verma et al., Firmicutes were reported at a maximum of $36.7 \%$, Bacteroidetes at $17.1 \%$, Proteobacteria at $17.1 \%$, Actinobacteria at $11.6 \%$, Spirochaetes at $7.9 \%$ and Fusobacteria at $5.2 \%$ [10]. In the present work, the phyla occur with similar frequency (Figure 12), although the frequency of the Spirochaetes was significantly lower. In terms of genus level, several authors have reported an oral core microbiome [10,36]. According to Bik et al. [37], this includes the genera Actinomyces, Atopobium, Corynebacterium and Rothia of the phylum Actinobacteria; the genera Bergeyella, Capnocytophaga and Prevotella of the phylum Bacteroidetes; the genera Granulicatella, Streptococcus and Veillonella of the phylum Firmicutes; the genera Campylobacter, Cardiobacterium, Haemophilus and Neisseria of the phylum Proteobacteria as well as Fusobacteria and TM7. The genera Derxia and Leptotrichia were added later by Chen et al. [10,16]. With the exception of the genera Bergeyella, Derxia and Granulicatella, these genera were also detected in the present study in correspondingly relevant frequencies. In contrast, the genera Chryseobacterium, Anaeroglobus, Filifactor, Lactobacillus, Johnsonella, Shuttleworthia, Brachymonas, Propiniovibri, Scardovia, Olsenella, Cryptobacterium, Bulleidia, Peptostreptococcus, Dialister, Gemella, Selenomonas, Oribacterium, Eikenella, Kingella, Lautropia, Propionibacterium and Porphyromonas are classified as variable oral microbiome [10,37]. In the present study, most of these genera also occurred sporadically, but the genera Porphyromonas $(1.5 \%)$ and Alloprevotella $(1.4 \%)$ were also found here with a notable frequency of more than $1 \%$ in the median salivary microbiome. The genera Tannerella $(0.1 \%)$, Parvimonas $(0.2 \%)$ and Filifactor $(0.02 \%)$ were also found consistently and in relevant abundance in the saliva of almost all abscess patients. All five genera have been frequently associated with periodontal or apical inflammatory processes $[3,38,39]$ and could be a possible indicator of a more aggressive variable oral microbiome in patients with extensive odontogenic abscesses.

\subsection{Microbiome of the Pus}

As in other previously conducted molecular biological studies on the bacterial spectrum in the pus of odontogenic abscesses, it was shown that the odontogenic infections were usually not only polymicrobial in nature, but that a much higher number of bacteria could be detected by molecular biological methods than by conventional culture-based detection [3]. With a mean number of $31.44( \pm 12.09)$ genera in the pus, a separate microbiome of the pus is obvious. There was no case where no bacteria could be detected in the pus. Thus, a situation comparable to a culture-negative abscess could not be observed. In contrast to the polymicrobial nature of odontogenic abscesses, in 2 out of 50 cases, a different scenario emerged, with a strong predominance of only one genus. This was, in both 
cases, the genus Streptococcus, which played a much smaller role in the pus microbiomes of the other 48 samples, as shown in the heatmaps of Figures 7 and 8 . It is possible that the molecular detection method in two samples revealed a real mono-infection with a "culprit bacterium", which probably belonged to normal oral Streptococcus. In the remaining 48 samples, however, as in other studies, there was a strong predominance of anaerobic genera, while the facultative anaerobic genus Streptococcus played only a subordinate role (Figure 10). The anaerobic genera were, in particular, associated with the development of acute symptoms in apical periodontal lesions in the work of Siqueira and Rôças [3]. The results of the present study thus underline the assumption that mainly bacteria of the genera Prevotella, Porphyromonas, Fusobacterium, Veillonella and Parvimonas are involved in the formation of acute dentogenic abscesses, even if these bacteria also occur with equal abundance in the root canal in asymptomatic chronic apical periodontitis [40,41]. Principal component analysis (Figure 9) further shows that even bacteria with a lower abundance, such as Mogibacterium, Filifactor, Slackia and Peptostreptococcus, may also be characteristic for the microbiological community of an odontogenic abscess.

Veillonella, the fourth most common genus of the median pus microbiome, is an early colonizer of oral biofilms and a causative agent of opportunistic infections [42]. In the present study, Veillonella shows a similar distribution to the genus Streptococcus in both saliva and pus. An interaction with Streptococcus in the development of caries [43] as well as the typical presence in the root canal with endodontic infections has been described [44]. Rôças et al. have described in their study that $V$. parvula produces menaquinones that can meet the specific nutrient requirements of Porphyromonas and Prevotella species for this substance [44]. In addition, V. parvula was found to promote the growth of T. denticola in co-cultures by providing peptidase activities complementary to those of T. denticola $[44,45]$. The genus Veillonella thus appears to be an important member of a pathogenic microbial community together with Porphyromonas, Prevotella and Treponema.

The abundance of the genus Mogibacterium is also worth mentioning. With a proportion of $1.8 \%$ of the median pus microbiome, the frequency is almost as high as that of the genus Streptococcus at $2.0 \%$. Although no direct correlation between odontogenic abscesses and an increased occurrence of Mogibacterium has been described so far, there are indeed reports that Mogibacterium can occur more frequently in association with pathological processes $[46,47]$. For instance, the genus Mogibacterium is thought to play a role in the development of inflammation in bisphosphonate-associated bone necrosis of the jaw, together with the genera Porphyromonas and Treponema [48]. Another study reports the frequent occurrence of Mogibacterium in the root canal before and after endodontic treatment [49]. Mogibacterium may therefore play a greater role in the development of odontogenic abscesses than previously thought. Another genus, the eighth most abundant one, was the genus Filifactor, accounting for $0.8 \%$ of the median microbiome. For the species Filifactor alocis, it has been described that the bacterium, which is very difficult to cultivate, plays a role in both marginal periodontitis and endodontic infection [49-52]. It is often reported that this pathogen may play a much more important role in the pathogenesis of inflammatory processes than had been assumed in the past [52].

\subsection{Pathogenicity of the Pus Microbiome}

Overall, the results of our study seem to show a clear shift in pathogenicity from the microbiome of saliva to the microbiome of pus. Thus, pathogenicity mechanisms have been reported for many of the genera commonly found in pus [48,53-56] and the importance of bacterial communities has often been highlighted $[3,10,31]$. In this context, the bacterial complexes described by Socransky in the development of periodontal diseases in particular became well-known [21,54]. Figure 11 represents an attempt to assign the bacterial genera to a specific habitat or group. Potentially pathogenic bacteria such as Prevotella, Fusobacterum or Parvimonas were therefore assigned to the "orange complex" because of a possible or probable affiliation and genera such as Porphyromonas, Tannerella and Treponema to the "red complex". The remaining genera were assigned to their natural habitat 
because of their potentially lower pathogenicity. For example, Neisseria, Haemophilus or Streptococcus were assigned to the "oral cavity" habitat according to their importance in the oral microbiome [10]. Looking at these classifications according to potential pathogenicity, a clear shift towards pathogenicity (orange and red complex) can be seen between their frequency in saliva and their frequency in pus. The microbiome of the abscess is therefore by no means a simple dissipated amount of oral or pharyngeal microbiome. Instead, it is obviously a collection of bacteria and bacterial communities with high pathogenicity.

\subsection{Phylum-Level Diversity and the Importance of Streptococcus}

Looking at the median microbiome of the pus at the phylum level, it can be seen that Bacteroidetes (including Prevotella and Porphyromonas) had by far the largest share of $69 \%$, while Firmicutes (including Streptococcus, Veillonella and Parvimonas) had a share of only $14 \%$ and Fusobacteria had a share of $16 \%$. Compared to other studies based on culturebased methods, the proportion of Firmicutes in our work was significantly lower and the proportion of Bacteroidetes significantly higher $[3,57,58]$. In studies based on molecular methods, a lower proportion of Firmicutes was also shown, but this was still significantly higher than in our work, at $38 \%$ to $64 \%$. [3]. It is remarkable that almost no Proteobacteria (Campylobacter, Cardiobacterium, Haemophilus, Neisseria, among others) were detected in the abscess by molecular methods, as also seen in this work [3]. It is possible that the detection of these genera by culture is a result of contamination by saliva during sampling. A similar picture emerges looking at the frequently detected genus Streptococcus.

In the present molecular study, the genus Streptococcus showed a much more dominant occurrence in the salivary microbiome than in the abscess microbiome, which was also confirmed by other authors [10]. However, Streptococcus in particular is very frequently detected in pure culture-based detection methods due to their easy cultivation. In contrast, cultivation of anaerobic bacteria is much more delicate, resulting in less frequent detection [24,30,57,59-62]. It can therefore be assumed that the culture-based detection of Streptococcus in odontogenic abscesses, as well as the antibiogram produced by this, may be attributed greater importance than is actually the case. It is quite conceivable that bacteria of the genera Prevotella, Porphyromonas, Fusobacterium and Parvimonas are not sufficiently detected by the current culture-based methods and thus no suitable antibiogram can be prepared for the actual "culprit" pathogens of the abscess. This would imply that many culture-based pathogen detection methods for effective therapy adjustment would not only be delayed, but the antibiograms thus generated would even be of questionable relevance. However, predominantly, bacteria of the genera Fusobacterium and Porphyromonas have been associated with acute exacerbations and strong pathogenicity $[3,33,53,55]$ and frequent resistance to common antibiotics has already been reported for the equally pathogenic bacteria of the genus Prevotella [63-65]. The question therefore emerges as to whether the solely culture-based evidence, as currently established in many hospitals, is still up to date given the current technical possibilities. In fact, most odontogenic abscesses are probably treated adequately and successfully by early abscess incision and, if there is a tendency to spread, by additional adequate calculated antibiotic therapy even without the availability of an antibiogram [1]. However, particularly in cases of very extensive abscesses that do not respond adequately to therapeutic efforts, adequate bacterial detection with preparation of an appropriate antibiogram can be of critical importance to patient outcomes. For these cases, it is necessary to demand that prompt bacterial determination by molecular biological methods should be introduced as soon as possible as a part of the clinical routine diagnostics.

\section{Conclusions}

1. The oral microbiome of patients with odontogenic abscesses was comparable to that of healthy subjects described in the literature, although very individual. However, the individually variable microbiome could possibly contain more bacteria with increased pathogenic potential. 
2. Odontogenic infections are mainly polymicrobial (96\%) and rarely mono-infections $(4 \%)$. Similar to saliva, pus showed its own microbiome, with a mean number of 31.44 $( \pm 12.09)$ genera.

3. Odontogenic abscesses are mainly caused by anaerobic bacterial strains. Aerobic and facultative anaerobic bacteria seem to play a minor role compared to previously published results described by other authors.

4. The most abundant genera in the pus were Prevotella, Porphyromonas and Fusobacterium, followed by Veillonella, Parvimonas, Streptococcus, Mogibacterium and Filifactor.

5. The pus microbiomes likely have a much higher pathogenic potential than the oral microbiomes derived from saliva.

6. Microbiome analysis detects significantly more bacteria than conventional culturebased methods and shows results even in the case of culture-negative samples. Molecular methods are expected to become the gold standard in medical microbiology diagnostics, particularly for polymicrobial infections with a predominance of anaerobic bacteria.

Author Contributions: Conceptualization, S.B., J.-F.W., H.-P.H., E.D. and S.A.; Data curation, S.B. and M.K.; Formal analysis, J.P.-K.; Investigation, S.B., S.Z.-G., D.S., T.H., M.W. and E.D.; Methodology, P.S. and E.D.; Project administration, S.A.; Supervision, H.-P.H. and S.A.; Validation, S.B. and H.-P.H.; Writing—original draft, S.B.; Writing—review and editing, S.Z.-G., D.S., P.S., J.-F.W., M.K., J.P.-K., T.H., M.W., H.-P.H., E.D. and S.A. All authors have read and agreed to the published version of the manuscript.

Funding: The study was funded collaboratively by the Institute of Medical Microbiology and the Clinic for Oral and Maxillofacial Surgery of the Justus-Liebig-University Giessen. This study was supported by the German Research Foundation DFG (KFO 309 Z01, SFB1021 Z02 and SFB-TR84 $\mathrm{B} / 08)$ to $\mathrm{TH}$.

Institutional Review Board Statement: The study was approved by the Ethics Committee of the Medical Faculty of the Justus-Liebig-University Giessen (Vote 191/16).

Informed Consent Statement: Informed consent was obtained from all subjects involved in the study.

Data Availability Statement: The datasets generated during and/or analyzed during the current study are available from the corresponding author on reasonable request.

Acknowledgments: The authors thank Trinad Chakraborty (Institute of Medical Microbiology) for making sequencing machines available.

Conflicts of Interest: The authors declare no competing interests.

\section{References}

1. Al-Nawas, B.; Karbach, J. S3-Leitlinie (Langversion): Odontogene Infektionen. In Leitlinien Zahnmedizin; Arbeitsgemeinschaft der Wissenschaftlichen Medizinischen Fachgesellschaften: Berlin, Germany, 2016; Available online: www.awmf.org (accessed on 10 March 2020).

2. Al-Nawas, B.; Maeurer, M. Severe versus Local Odontogenic Bacterial Infections: Comparison of Microbial Isolates. Eur. Surg. Res. 2007, 40, 220-224. [CrossRef] [PubMed]

3. Siqueira, J.F.; Rôças, I.N. Microbiology and Treatment of Acute Apical Abscesses. Clin. Microbiol. Rev. 2013, 26, 255-273. [CrossRef]

4. Warnke, P.H.; Becker, S.T.; Springer, I.N.; Haerle, F.; Ullmann, U.; Russo, P.A.; Wiltfang, J.; Fickenscher, H.; Schubert, S. Penicillin compared with other advanced broad spectrum antibiotics regarding antibacterial activity against oral pathogens isolated from odontogenic abscesses. J. Cranio-Maxillofac. Surg. 2008, 36, 462-467. [CrossRef] [PubMed]

5. Böttger, S.; Lautenbacher, K.; Domann, E.; Howaldt, H.-P.; Attia, S.; Streckbein, P.; Wilbrand, J.-F. Indication for an additional postoperative antibiotic treatment after surgical incision of serious odontogenic abscesses. J. Cranio-Maxillofac. Surg. 2020, 48, 229-234. [CrossRef]

6. Flynn, T.R. The swollen face. Severe odontogenic infections. Emerg. Med. Clin. N. Am. 2000, 18, 481-519. [CrossRef]

7. Eckert, A.W.; Maurer, P.; Wilhelms, D.; Schubert, J. Soft tissue infections in oral, maxillofacial, and plastic surgery. Bacterial spectra and antibiotics. Mund. Kiefer Gesichtschir. 2005, 9, 389-395. [CrossRef] [PubMed] 
8. Bali, R.K.; Sharma, P.; Gaba, S.; Kaur, A.; Ghanghas, P. A review of complications of odontogenic infections. Natl. J. Maxillofac. Surg. 2015, 6, 136-143. [CrossRef]

9. Palma, D.M.; Giuliano, S.; Cracchiolo, A.N.; Falcone, M.; Ceccarelli, G.; Tetamo, R.; Venditti, M. Clinical features and outcome of patients with descending necrotizing mediastinitis: Prospective analysis of 34 cases. Infection 2015, 44, 77-84. [CrossRef]

10. Verma, D.; Garg, P.K.; Dubey, A.K. Insights into the human oral microbiome. Arch. Microbiol. 2018, 200, 525-540. [CrossRef] [PubMed]

11. Wiese, K.G.; Merten, H.A.; Wiltfang, J.; Luhr, H.G. Clinical studies on the pathophysiology of odontogenic abscesses. Mund Kiefer Gesichtschir. 1999, 3, 242-246. [CrossRef] [PubMed]

12. Siqueira, J.F., Jr.; Rôças, I.N. As-yet-uncultivated oral bacteria: Breadth and association with oral and extra-oral diseases. J. Oral Microbiol. 2013, 5, 21077. [CrossRef] [PubMed]

13. Böttger, S.; Zechel-Gran, S.; Streckbein, P.; Knitschke, M.; Hain, T.; Weigel, M.; Wilbrand, J.-F.; Domann, E.; Howaldt, H.-P.; Attia, S. A New Type of Chronic Wound Infection after Wisdom Tooth Extraction: A Diagnostic Approach with 16S-rRNA Gene Analysis, Next-Generation Sequencing, and Bioinformatics. Pathogens 2020, 9, 798. [CrossRef] [PubMed]

14. Siqueira, J.F.; Rôças, I.N. The Oral Microbiota in Health and Disease: An Overview of Molecular Findings. Methods Mol. Biol. 2017, 1537, 127-138. [CrossRef] [PubMed]

15. Voelkerding, K.V.; Dames, S.A.; Durtschi, J.D. Next-Generation Sequencing: From Basic Research to Diagnostics. Clin. Chem. 2009, 55, 641-658. [CrossRef]

16. Echen, H.; Ejiang, W. Application of high-throughput sequencing in understanding human oral microbiome related with health and disease. Front. Microbiol. 2014, 5, 508. [CrossRef]

17. Keller, P.M.; Hombach, M.; Bloemberg, G.V. 16S-rRNA-Gen-basierte Identifikation bakterieller Infektionen. Biospektrum 2010, 16, 755-758.

18. Griessl, T.; Zechel-Gran, S.; Olejniczak, S.; Weigel, M.; Hain, T.; Domann, E. High-resolution taxonomic examination of the oral microbiome after oil pulling with standardized sunflower seed oil and healthy participants: A pilot study. Clin. Oral Investig. 2021, 25, 2689-2703. [CrossRef]

19. Regier, Y.; Komma, K.; Weigel, M.; Kraiczy, P.; Laisi, A.; Pulliainen, A.T.; Hain, T.; Kempf, V.A.J. Combination of microbiome analysis and serodiagnostics to assess the risk of pathogen transmission by ticks to humans and animals in central Germany. Parasites Vectors 2019, 12, 11. [CrossRef] [PubMed]

20. Quast, C.; Pruesse, E.; Yilmaz, P.; Gerken, J.; Schweer, T.; Yarza, P.; Peplies, J.; Glöckner, F.O. The SILVA Ribosomal RNA Gene Database Project: Improved Data Processing and Web-Based Tools. Nucleic Acids Res. 2012, 41, D590-D596. [CrossRef]

21. Socransky, S.S.; Haffajee, A.D.; Cugini, M.A.; Smith, C.; Kent, R.L., Jr. Microbial complexes in subgingival plaque. J. Clin. Periodontol. 1998, 25, 134-144. [CrossRef]

22. Sizova, M.V.; Hohmann, T.; Hazen, A.; Paster, B.J.; Halem, S.R.; Murphy, C.M.; Panikov, N.S.; Epstein, S.S. New Approaches for Isolation of Previously Uncultivated Oral Bacteria. Appl. Environ. Microbiol. 2011, 78, 194-203. [CrossRef] [PubMed]

23. Socransky, S.S.; Gibbons, R.J.; Dale, A.C.; Bortnick, L.; Rosenthal, E.; Macdonald, J.B. The microbiota of the gingival crevice area of man. I. Total microscopic and viable counts and counts of specific organisms. Arch. Oral Biol. 1963, 8, 275-280. [CrossRef]

24. Heim, N.; Faron, A.; Wiedemeyer, V.; Reich, R.; Martini, M. Microbiology and antibiotic sensitivity of head and neck space infections of odontogenic origin. Differences in inpatient and outpatient management. J. Cranio-Maxillofac. Surg. 2017, 45, 1731-1735. [CrossRef] [PubMed]

25. Flynn, T.R.; Shanti, R.M.; Hayes, C. Severe Odontogenic Infections, Part 2: Prospective Outcomes Study. J. Oral Maxillofac. Surg. 2006, 64, 1104-1113. [CrossRef] [PubMed]

26. Chandra, H.J.; Rao, B.H.S.; Manzoor, A.P.M.; Arun, A.B. Characterization and Antibiotic Sensitivity Profile of Bacteria in Orofacial Abscesses of Odontogenic Origin. J. Maxillofac. Oral Surg. 2016, 16, 445-452. [CrossRef] [PubMed]

27. Opitz, D.; Camerer, C.; Camerer, D.-M.; Raguse, J.-D.; Menneking, H.; Hoffmeister, B.; Adolphs, N. Incidence and management of severe odontogenic infections-A retrospective analysis from 2004 to 2011. J. Cranio-Maxillofac. Surg. 2015, 43, 285-289. [CrossRef]

28. Lee, Y.Q.; Kanagalingam, J. Bacteriology of deep neck abscesses: A retrospective review of 96 consecutive cases. Singap. Med. J. 2011, 52, 351-355. [CrossRef]

29. Celakovsky, P.; Kalfert, D.; Smatanova, K.; Tuček, L.; Čermáková, E.; Mejzlik, J.; Kotulek, M.; Vrbacky, A.; Matoušek, P.; Stanikova, L.; et al. Bacteriology of deep neck infections: Analysis of 634 patients. Aust. Dent. J. 2015, 60, 212-215. [CrossRef]

30. Poeschl, P.W.; Spusta, L.; Russmueller, G.; Seemann, R.; Hirschl, A.; Poeschl, E.; Klug, C.; Ewers, R. Antibiotic susceptibility and resistance of the odontogenic microbiological spectrum and its clinical impact on severe deep space head and neck infections. Oral Surg. Oral Med. Oral Pathol. Oral Radiol. Endodontol. 2010, 110, 151-156. [CrossRef] [PubMed]

31. Siqueira, J.F.; Rôças, I.N. Community as the unit of pathogenicity: An emerging concept as to the microbial pathogenesis of apical periodontitis. Oral Surg. Oral Med. Oral Pathol. Oral Radiol. Endodontol. 2009, 107, 870-878. [CrossRef] [PubMed]

32. Munson, M.A.; Pitt-Ford, T.; Chong, B.; Weightman, A.; Wade, W.G. Molecular and Cultural Analysis of the Microflora Associated with Endodontic Infections. J. Dent. Res. 2002, 81, 761-766. [CrossRef]

33. Jenkinson, H.F.; Lamont, R.J. Oral microbial communities in sickness and in health. Trends Microbiol. 2005, 13, 589-595. [CrossRef]

34. Dewhirst, F.E.; Chen, T.; Izard, J.; Paster, B.J.; Tanner, A.C.R.; Yu, W.-H.; Lakshmanan, A.; Wade, W.G. The Human Oral Microbiome. J. Bacteriol. 2010, 192, 5002-5017. [CrossRef] 
35. Chen, T.; Yu, W.-H.; Izard, J.; Baranova, O.V.; Lakshmanan, A.; Dewhirst, F.E. The Human Oral Microbiome Database: A web accessible resource for investigating oral microbe taxonomic and genomic information. Database 2010, baq013. [CrossRef]

36. Zaura, E.; Keijser, B.J.F.; Huse, S.M.; Crielaard, W. Defining the healthy "core microbiome" of oral microbial communities. BMC Microbiol. 2009, 9, 259. [CrossRef] [PubMed]

37. Bik, E.M.; Long, C.D.; Armitage, G.C.; Loomer, P.; Emerson, J.; Mongodin, E.F.; Nelson, K.E.; Gill, S.R.; Fraser-Liggett, C.M.; Relman, D.A. Bacterial diversity in the oral cavity of 10 healthy individuals. ISME J. 2010, 4, 962-974. [CrossRef] [PubMed]

38. Chen, H.; Liu, Y.; Zhang, M.; Wang, G.; Qi, Z.; Bridgewater, L.; Zhao, L.; Tang, Z.; Pang, X. A Filifactor alocis-centered co-occurrence group associates with periodontitis across different oral habitats. Sci. Rep. 2015, 5, 9053. [CrossRef]

39. Nibali, L.; Sousa, V.; Davrandi, M.; Spratt, D.; Alyahya, Q.; Dopico, J.; Donos, N. Differences in the periodontal microbiome of successfully treated and persistent aggressive periodontitis. J. Clin. Periodontol. 2020, 47, 980-990. [CrossRef] [PubMed]

40. Siqueira, J.F.; Rôças, I.N.; Souto, R.; de Uzeda, M.; Colombo, A.P. Microbiological evaluation of acute periradicular abscesses by DNA-DNA hybridization. Oral Surg. Oral Med. Oral Pathol. Oral Radiol. Endodontol. 2001, 92, 451-457. [CrossRef]

41. Van Winkelhoff, A.J.; Carlee, A.W.; de Graaff, J. Bacteroides endodontalis and other black-pigmented Bacteroides species in odontogenic abscesses. Infect. Immun. 1985, 49, 494-497. [CrossRef]

42. Mashima, I.; Kamaguchi, A.; Nakazawa, F. The Distribution and Frequency of Oral Veillonella spp. in the Tongue Biofilm of Healthy Young Adults. Curr. Microbiol. 2011, 63, 403-407. [CrossRef] [PubMed]

43. Liu, S.; Chen, M.; Wang, Y.; Zhou, X.; Peng, X.; Ren, B.; Li, M.; Cheng, L. Effect of Veillonella parvula on the physiological activity of Streptococcus mutans. Arch. Oral Biol. 2020, 109, 104578. [CrossRef] [PubMed]

44. Rôças, I.; Siqueira, J. Culture-Independent Detection of Eikenella corrodens and Veillonella parvula in Primary Endodontic Infections. J. Endod. 2006, 32, 509-512. [CrossRef]

45. Ter Steeg, P.F.; Van Der Hoeven, J.S. Growth stimulation of Treponema denticola by periodontal microorganisms. Antonie Leeuwenhoek 1990, 57, 63-70. [CrossRef] [PubMed]

46. Coker, O.O.; Dai, Z.; Nie, Y.; Zhao, G.; Cao, L.; Nakatsu, G.; Wu, W.K.; Wong, S.H.; Chen, Z.; Sung, J.J.Y.; et al. Mucosal microbiome dysbiosis in gastric carcinogenesis. Gut 2018, 67, 1024-1032. [CrossRef] [PubMed]

47. Stehlikova, Z.; Tlaskal, V.; Galanova, N.; Roubalova, R.; Kreisinger, J.; Dvorak, J.; Prochazkova, P.; Kostovcikova, K.; Bartova, J.; Libanska, M.; et al. Oral Microbiota Composition and Antimicrobial Antibody Response in Patients with Recurrent Aphthous Stomatitis. Microorganisms 2019, 7, 636. [CrossRef] [PubMed]

48. Li, Q.; Pu, Y.; Lu, H.; Zhao, N.; Wang, Y.; Guo, Y.; Guo, C. Porphyromonas, Treponema, and Mogibacterium promote IL8/IFN $\gamma / T N F \alpha-$ based pro-inflammation in patients with medication-related osteonecrosis of the jaw. J. Oral Microbiol. 2020, $13,1851112$. [CrossRef]

49. Gomes, B.P.; Berber, V.B.; Kokaras, A.S.; Chen, T.; Paster, B.J. Microbiomes of Endodontic-Periodontal Lesions before and after Chemomechanical Preparation. J. Endod. 2015, 41, 1975-1984. [CrossRef]

50. Gomes, B.P.; Louzada, L.M.; Almeida-Gomes, R.F.; Pinheiro, E.T.; Sousa, E.L.; Jacinto, R.C.; Arruda-Vasconcelos, R. Investigation of Filifactor alocis in primary and in secondary endodontic infections: A molecular study. Arch. Oral Biol. 2020, 118, 104826. [CrossRef]

51. Aruni, A.W.; Mishra, A.; Dou, Y.; Chioma, O.; Hamilton, B.N.; Fletcher, H.M. Filifactor alocis-A new emerging periodontal pathogen. Microbes Infect. 2015, 17, 517-530. [CrossRef]

52. Aruni, W.; Chioma, O.; Fletcher, H. Filifactor alocis: The Newly Discovered Kid on the Block with Special Talents. J. Dent. Res. 2014, 93, 725-732. [CrossRef] [PubMed]

53. Han, Y.W. Fusobacterium nucleatum: A commensal-turned pathogen. Curr. Opin. Microbiol. 2015, 23, 141-147. [CrossRef] [PubMed]

54. Holt, S.C.; Ebersole, J.L. Porphyromonas gingivalis, Treponema denticola, and Tannerella forsythia: The 'red complex', a prototype polybacterial pathogenic consortium in periodontitis. Periodontology 2000 2005, 38, 72-122. [CrossRef]

55. Jun, H.-K.; Jung, Y.-J.; Choi, B.-K. Treponema denticola, Porphyromonas gingivalis, and Tannerella forsythia induce cell death and release of endogenous danger signals. Arch. Oral Biol. 2017, 73, 72-78. [CrossRef] [PubMed]

56. Mysak, J.; Podzimek, S.; Sommerova, P.; Lyuya-Mi, Y.; Bartova, J.; Janatova, T.; Prochazkova, J.; Duskova, J. Porphyromonas gingivalis: Major Periodontopathic Pathogen Overview. J. Immunol. Res. 2014, 2014, 1-8. [CrossRef]

57. Williams, B.L.; McCann, G.F.; Schoenknecht, F.D. Bacteriology of dental abscesses of endodontic origin. J. Clin. Microbiol. 1983, 18, 770-774. [CrossRef] [PubMed]

58. Khemaleelakul, S.; Baumgartner, J.; Pruksakorn, S. Identification of bacteria in acute endodontic infections and their antimicrobial susceptibility. Oral Surg. Oral Med. Oral Pathol. Oral Radiol. Endodontol. 2002, 94, 746-755. [CrossRef]

59. Plum, A.W.; Mortelliti, A.J.; Walsh, R.E. Microbial Flora and Antibiotic Resistance in Odontogenic Abscesses in Upstate New York. Ear Nose Throat J. 2018, 97, E27-E31. [CrossRef]

60. Shakya, N.; Sharma, D.; Newaskar, V.; Agrawal, D.; Shrivastava, S.; Yadav, R. Epidemiology, Microbiology and Antibiotic Sensitivity of Odontogenic Space Infections in Central India. J. Maxillofac. Oral Surg. 2018, 17, 324-331. [CrossRef] [PubMed]

61. Heimdahl, A.; Von Konow, L.; Satoh, T.; Nord, C.E. Clinical appearance of orofacial infections of odontogenic origin in relation to microbiological findings. J. Clin. Microbiol. 1985, 22, 299-302. [CrossRef] [PubMed]

62. Bahl, R.; Sandhu, S.; Sahai, N.; Gupta, M.; Singh, K. Odontogenic infections: Microbiology and management. Contemp. Clin. Dent. 2014, 5, 307-311. [CrossRef] [PubMed] 
63. Kuriyama, T.; Williams, D.W.; Yanagisawa, M.; Iwahara, K.; Shimizu, C.; Nakagawa, K.; Yamamoto, E.; Karasawa, T. Antimicrobial susceptibility of 800 anaerobic isolates from patients with dentoalveolar infection to 13 oral antibiotics. Oral Microbiol. Immunol. 2007, 22, 285-288. [CrossRef] [PubMed]

64. Liu, C.-Y.; Huang, Y.-T.; Liao, C.-H.; Yen, L.-C.; Lin, H.-Y.; Hsueh, P.-R. Increasing Trends in Antimicrobial Resistance among Clinically Important Anaerobes and Bacteroides fragilis Isolates Causing Nosocomial Infections: Emerging Resistance to Carbapenems. Antimicrob. Agents Chemother. 2008, 52, 3161-3168. [CrossRef] [PubMed]

65. Sherrard, L.J.; Graham, K.A.; McGrath, S.J.; McIlreavey, L.; Hatch, J.; Muhlebach, M.S.; Wolfgang, M.C.; Gilpin, D.F.; Elborn, J.S.; Schneiders, T.; et al. Antibiotic resistance in Prevotella species isolated from patients with cystic fibrosis. J. Antimicrob. Chemother. 2013, 68, 2369-2374. [CrossRef] 